\title{
Radio variability properties for radio sources ${ }^{\star}$
}

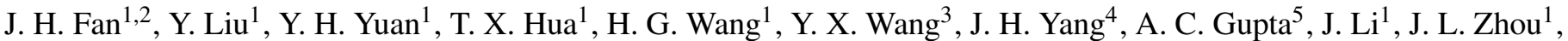 \\ S. X. Xu' ${ }^{1}$, and J. L. Chen ${ }^{1}$ \\ ${ }^{1}$ Center for Astrophysics, Guangzhou University, Guangzhou 510006, PR China \\ e-mail: fjh@gzhu.edu.cn \\ 2 Physics Institute, Hunan Normal University, Changsha, PR China \\ 3 College of Science and Trade, Guangzhou University, Guangzhou 511442, PR China \\ ${ }^{4}$ Department of Physics and Electronics Science, Hunan University of Arts and Science, Changde 415000, PR China \\ 5 Tata Institute of Fundamental Research, Homi Bhabha Road, Colaba, Mumbai - 400005, India
}

Received 25 December 2005 / Accepted 1 October 2006

\section{ABSTRACT}

\begin{abstract}
In this paper, we used the database of the university of Michigan Radio Astronomy Observatory (UMRAO) at three (4.8 GHz, 8.0 GHZ, and $14.5 \mathrm{GHz}$ ) radio frequency to analyze the radio light curves by the power spectral analysis method in search of possible periodicity. The analysis results showed that the radio sources display astrophysically meaningful periodicity ranging from 2.2 to 20.8 years in their light curves at the three frequencies. We also calculated the variability parameters and investigated the correlations between the variability parameter and the flux density. For the variability parameters, we found that the parameters at higher frequency are higher than those in the lower frequency. In addition, the variability parameters of BL Lacertae objects are larger than those of flat-spectrum radio quasars. suggesting that they are more variable than flat spectrum radio quasars.
\end{abstract}

Key words. BL lacertae objects: general - quasars: general - methods: data analysis

\section{Introduction}

The nature of the central engine of blazars and other classes of active galactic nuclei (AGNs) is still an open problem. Blazars' light curves were generated by using the data of their monitoring program, which have yielded very valuable information about the mechanisms operating in these sources and important implications for quasar modeling (Fan et al. 1998). In the past two decades, optical monitoring program of blazars and other classes of AGNs have been conducted extensively by many groups around the globe, and blazars were reported to display flux variability on diverse time scales ranging from a few minutes to hours, to days, to months, and to even more than 10 years (Fan 2005b). The variability time scale on years gives the longterm variation information in the source and an important tool predicting other outburst times.

Radio monitoring programs were carried out at Bologna at $408 \mathrm{MHz}$ (Bondi et al. 1996), Michigan University at $4.8 \mathrm{GHz}$, $8 \mathrm{GHz}, 14.5 \mathrm{GHz}$, and Metsähovi observatory at $22 \mathrm{GHz}$, $37 \mathrm{GHz}, 87 \mathrm{GHz}$, ESO site on Cerro La Silla, Chile, at $90 \mathrm{GHz}$ and $230 \mathrm{GHz}$ (Tornikoski et al. 1996). Using the data of these monitoring, many groups have investigated the variability properties and found that blazars show interesting results. Based on this radio data base, Kraus et al. (1999) report that blazars' emission is strongly beamed, Lahteenmaki \& Valtaoja (1999) estimated the radio Doppler factors for a sample of radio sources, Ciaramella et al. (2004) investigated the possible periodicity for several selected objects, and Aller et al. (2003) investigated other variability properties.

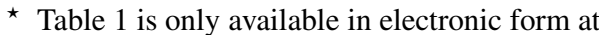
http: //www . aanda.org
In this paper, we make use of the UMRAO data base to investigate the possible periodicity, the variability parameter, and the correlation between the source brightness and the variability parameter. Section 2 presents the details about periodicity analysis method, Sect. 3 variability parameter, Sect. 4 , the results of the present work, and in Sect. 5 our discussions and conclusions are given.

\section{Power spectral (Fourier) periodicity analysis method and results}

There are many methods of time series data analysis. The fact that the astronomical observations are generally not evenly sampled will put some constraints on the analysis methods. In this paper, we used the power spectral analysis to search periodicity in the radio light curves of radio sources because it is a powerful and familiar method for detecting a periodic signal, and it gives some quantitative criteria for the detection of a periodic signal.

Many attempts at power spectral analysis have been made for the case that the data are unevenly spaced in time. the modified periodogram was widely used by astronomers (Scargle 1982; Horne \& Baliunas 1986), it is based on a least-square regression onto the two trial functions, $\sin (\omega t)$ and $\cos (\omega t)$. A superior technigue is the date-compensated discrete Fourier transform, or DCDFT (Ferraz-Mello 1981; Foster 1995), a least-square regression on $\sin (\omega t), \cos (\omega t)$ and constant. The DCDFT is a more powerful method than the modified periodogram for unevenlyspaced data, so we adopted it to the $R$ light curve as Foster (1995) describes.

The observed data $x\left(t_{i}\right)$ can define the data vector

$|x\rangle=\left[x\left(t_{1}\right), x\left(t_{2}\right), \cdots, x\left(t_{N}\right)\right]$. 
First, defining the inner product of two funcitons $f$ and $g$ as the average value of the product $f^{*} g$ over the observation times $\left\{t_{n}\right\}$, we get

$\langle f \mid g\rangle=\left(\frac{1}{N}\right) \sum_{n=1}^{N} f^{*}\left(t_{n}\right) g\left(t_{n}\right)$.

A subspace are spanned by 3 trial functions $\phi_{1}(t)=1$ (constant), $\phi_{2}(t)=\sin (\omega t)$, and $\phi_{3}(t)=\cos (\omega t)$. These 3 trial functions define a set of trial vectors,

$\left|\phi_{\alpha}\right\rangle=\left[\phi_{\alpha}\left(t_{1}\right), \phi_{\alpha}\left(t_{2}\right), \cdots, \phi_{\alpha}\left(t_{N}\right)\right], \alpha=1,2,3$.

The data vector $|x\rangle$ can be projected onto the subspace spanned by the $\left|\phi_{\alpha}\right\rangle$ results in a model vector $|y\rangle$ and a residual vector $|\Theta\rangle$,

$|x\rangle=|y\rangle+|\Theta\rangle$.

The model vector $|y\rangle$ is defined as

$|y\rangle=\sum_{\alpha} c_{\alpha}\left|\phi_{\alpha}\right\rangle$.

The $c_{\alpha}$ can be obtained by taking the inner product of each trial vector $\phi_{\alpha}$ with the data vector $x$, and we have

$\left\langle\phi_{\alpha} \mid x\right\rangle=\sum_{\beta} c_{\beta}\left\langle\phi_{\alpha} \mid \phi_{\beta}\right\rangle=\sum_{\beta} S_{\alpha \beta} c_{\beta}$,

which defines the $S$ matrix $S_{\alpha \beta}$. Inverting this matrix yields the coefficients,

$c_{\alpha}=\sum_{\beta} S_{\alpha \beta}^{-1}\left\langle\phi_{\beta} \mid x\right\rangle$,

where $s^{2}$ is the estimated data variance, and it can be replaced by $\delta^{2}$. The power level of DCDFT is,

$P_{X}(\omega)=\frac{1}{2} N\left[\langle y \mid y\rangle-\langle 1 \mid y\rangle^{2}\right] / s^{2}$

We adopted the false alarm probability, $F$ (Horne \& Baliunas 1986), to give a quantitative criterion for the detection of a periodic signal derived by DCDFT. It was done with the following steps. First, the power level of the periodogram is normalized by the total variance,

$P_{N}(\omega)=P_{X}(\omega) / \delta^{2}$.

The probability that $P_{N}\left(\omega_{0}\right)$ is of height $z$ or higher is $\operatorname{Pr}\left[P_{N}\left(\omega_{0}\right)>z\right]=\mathrm{e}^{-z}$. Suppose that $z$ is the highest peak in a periodogram that samples $N_{i}$ independent frequencies. The probability that each independent frequency is smaller than $z$ is $1-\mathrm{e}^{-z}$, so the probability that each frequency is lower than $z$ is $\left[1-\mathrm{e}^{-z}\right]^{N_{i}}$. Thus, the false alarm probability (FAP) can be defined,

$F=1-\left[1-\mathrm{e}^{-z}\right]^{N_{i}}$.

To compute FAP, we need to know $N_{i}$, which is not too difficult to obtain by a simple Monte Carlo method. The FAP tells us the probability that a peak of height $z$ will occur, assuming that the data are pure noise. Consequently, the quantity $1-F$ is the probability that the data contain a signal.

For illustration we present the analysis results in Fig. 1 for the strong sign of periods in $0605-085$ at $8 \mathrm{GHz}$, with the theoretical result obtained using two periods, namely a 7.16-year period with an amplitude of 0.582 and a 4.49-year period with an amplitude of 0.168 , and Fig. 2 for the weakest sign of periods in $1040+123$ at $8 \mathrm{GHz}$.
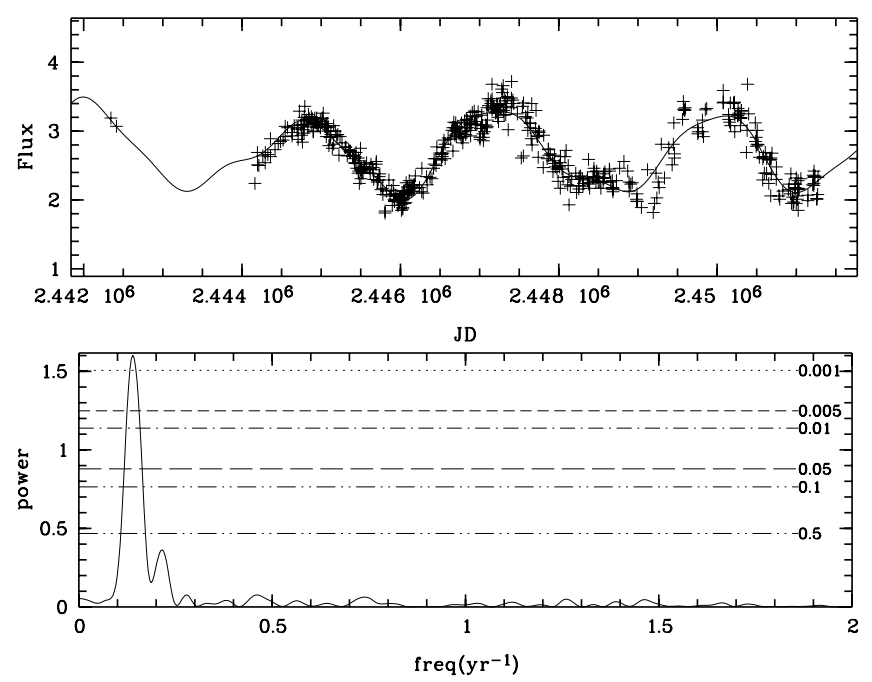

Fig. 1. The strong sign of periods in 0605-085 at $8 \mathrm{GHz}$. The upper panel is for the light curve at $8 \mathrm{GHz}$, while the lower panel is the power spectral analysis result.
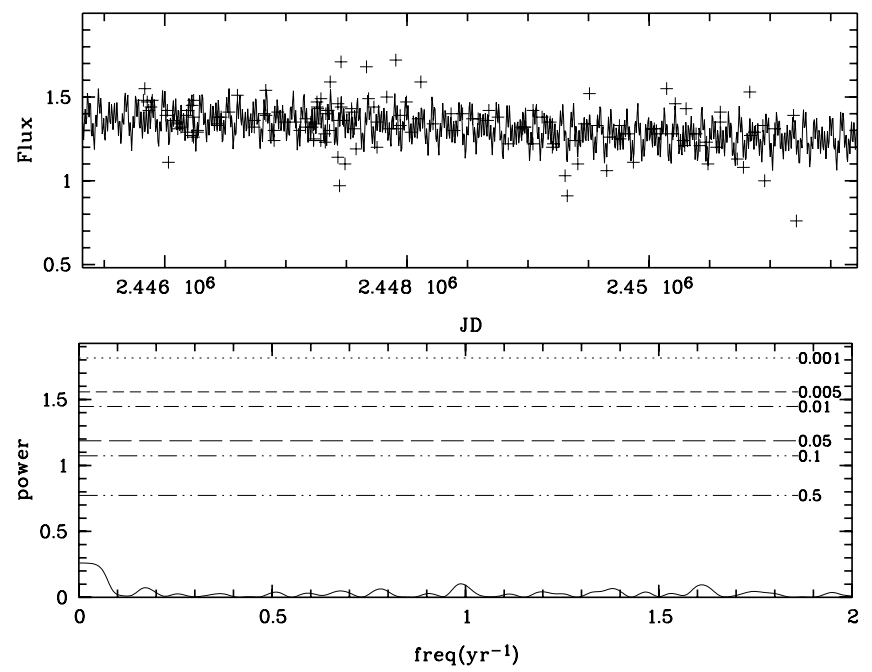

Fig. 2. The weakest sign of periods in $1040+123$ at $8 \mathrm{GHz}$. The upper panel is for the light curve at $8 \mathrm{GHz}$, while the lower panel is the power spectral analysis result.

\section{Variability parameter}

Blazars are variable in the entire electromagnetic wavebands. The variability violence can be expressed by the variability parameter. In the optical bands, the variability violence can be reported by using the variation parameters, such as variability parameter $C$ introduced by Romero et al. (1999). In radio bands, the variability violence is discussed using the variability index $(V I)$, the normalized variability amplitude (NVA), and the root mean square dispersion (RMSD). We described these radio variation parameters below.

\subsection{Variability index(VI)}

The variability index that measures the peak-to-trough variations in our flux density measurements can be calculated as introduced by Aller et al. (1992, 2003); Ciaramella et al. (2004):

$V I=\frac{\left(S_{\max }-\sigma_{S_{\max }}\right)-\left(S_{\min }+\sigma_{S_{\min }}\right)}{\left(S_{\max }-\sigma_{S_{\max }}\right)+\left(S_{\min }+\sigma_{S_{\min }}\right)}$, 
where $S_{\max }$ and $S_{\min }$ are the peak and the lowest flux densities, and $\sigma_{\mathrm{S}_{\max }}$ and $\sigma_{\mathrm{S}_{\min }}$ are the associated measurement errors of the fluxes.

\subsection{Normalized variability amplitude (NVA)}

The normalized variability amplitude (NVA) was calculated in the following way. For each band, the mean $\langle X\rangle$ and standard deviation $\sigma_{\text {tot }}$ of the flux points and the mean error level $\sigma_{\text {err }}$ were determined (Edelson et al. 1996). Since the NVA is free of the instrumental effect, it is calculated as

$N V A=\sqrt{\frac{\sigma_{\text {tot }}^{2}-\sigma_{\text {err }}^{2}}{\langle X\rangle^{2}}}$.

\subsection{Root mean square dispersion (RMSD)}

When a source has been observed at several epochs, whether the variability is a real one not can be determined by comparing the distribution of flux at the different epochs with a model in which the flux of the source is assumed to be non-variable (Edelson et al. 1992). If $S_{i}$ represents the measured fluxes, then the mean flux $\langle S\rangle$ and the root mean square dispersion as a fraction of the mean are given by following equations, respectively,

$\langle S\rangle=\frac{1}{N} \sum_{i=1}^{n} S_{i}$

$\sigma=\frac{1}{\langle S\rangle} \sqrt{\frac{1}{N-1} \sum_{i=1}^{n}\left(S_{i}-\langle S\rangle\right)^{2}}$

$\chi^{2}=\frac{1}{N} \sum_{i=1}^{n}\left(\frac{S_{i}-\langle S\rangle}{\sigma_{i}}\right)^{2}$

where $\sigma_{i}$ is the uncertainty in the individual measurement, and $\chi^{2}>1$ indicates that the assumption of non-variable flux is questionable (Kembhavi \& Narlika 1999).

\section{Results}

Periodicity results and the variability parameters of radio galaxies are reported in Table 1, in which Col. 1 represents the name of the source, Col. 2 Freq, the frequency in units of GHz, Col. 3 $\delta_{N}$, root mean square deviation, $\delta_{N}^{2}$ is the total variance of data, Col. $4 A$, the amplitude, Col. 5 the FAP of the determined period. Column $6 \mathrm{Tms}$, the determined period in units of years. The superscript " $F$ " means it is not a physically meaningful pe$\operatorname{riod}(F A P>0.5$ or Tms $>\mathrm{ObT})$, and the superscript "P" means it is a possible time scale $\left(F A P<0.5\right.$ and $\left.\frac{2}{3} \mathrm{ObT}<\mathrm{Tms}<\mathrm{ObT}\right)$. Column. 7 ObT indicates the time coverage of the light curve in units of years, Col. 8 the data points $(N)$, Col. 9 VI, Col. 10 NVA, Col. 11 RMSD, and Col. 12 the source identification (B for BL Lacertae, $Q$ for flat spectrum radio quasar-FSRQ and $G$ for galaxy).

For the whole and the subclass samples, the corresponding averaged values for the variability parameters are presented in Table 2 . The results based on the mutual correlation between different variability parameters are reported in Table 3 and plotted in Fig. 3.

The relationship between the variability parameters and brightness of the sources were determined by using the averaged $8 \mathrm{GHz}$ flux density. The results are listed in Table 4 and the corresponding results are shown in Fig. 4.
Table 2. Averaged variability parameters.

\begin{tabular}{lccc}
\hline \hline $\begin{array}{l}\text { Param. } \\
(1)\end{array}$ & $\begin{array}{c}14.5 \mathrm{GHz} \\
(2)\end{array}$ & $\begin{array}{c}8 \mathrm{GHz} \\
(3)\end{array}$ & $\begin{array}{c}4.8 \mathrm{GHz} \\
(4)\end{array}$ \\
\hline VI & $0.92 \pm 0.08$ & $0.90 \pm 0.09$ & $0.90 \pm 0.10$ \\
VI-BL & $0.90 \pm 0.10$ & $0.88 \pm 0.12$ & $0.84 \pm 0.14$ \\
VI-FSRQ & $0.94 \pm 0.05$ & $0.92 \pm 0.07$ & $0.93 \pm 0.06$ \\
VI-G & $0.89 \pm 0.09$ & $0.90 \pm 0.06$ & $0.93 \pm 0.05$ \\
\hline NVA & $0.23 \pm 0.13$ & $0.22 \pm 0.12$ & $0.16 \pm 0.12$ \\
NVA-BL & $0.30 \pm 0.12$ & $0.28 \pm 0.11$ & $0.24 \pm 0.11$ \\
NVA-FSRQ & $0.22 \pm 0.11$ & $0.21 \pm 0.11$ & $0.15 \pm 0.11$ \\
NVA-G & $0.10 \pm 0.04$ & $0.11 \pm 0.05$ & $0.04 \pm 0.03$ \\
\hline RMSD & $0.27 \pm 0.12$ & $0.27 \pm 0.11$ & $0.23 \pm 0.12$ \\
RMSD-BL & $0.33 \pm 0.11$ & $0.32 \pm 0.11$ & $0.29 \pm 0.11$ \\
RMSD-FSRQ & $0.25 \pm 0.10$ & $0.24 \pm 0.10$ & $0.20 \pm 0.10$ \\
RMSD-G & $0.17 \pm 0.03$ & $0.20 \pm 0.05$ & $0.15 \pm 0.03$ \\
\hline
\end{tabular}

Table 3. Correlation between variability parameters, $Y=a X+b$.

\begin{tabular}{lccc}
\hline \hline$X-Y$ & $a \pm \Delta a$ & $b \pm \Delta b$ & $r$ \\
$(1)$ & $(2)$ & $(3)$ & $(4)$ \\
\hline V.I.-NVA & $0.04 \pm 0.06$ & $0.89 \pm 0.02$ & 0.05 \\
RMSD-NVA & $0.84 \pm 0.03$ & $1.08 \pm 0.01$ & 0.893 \\
\hline
\end{tabular}

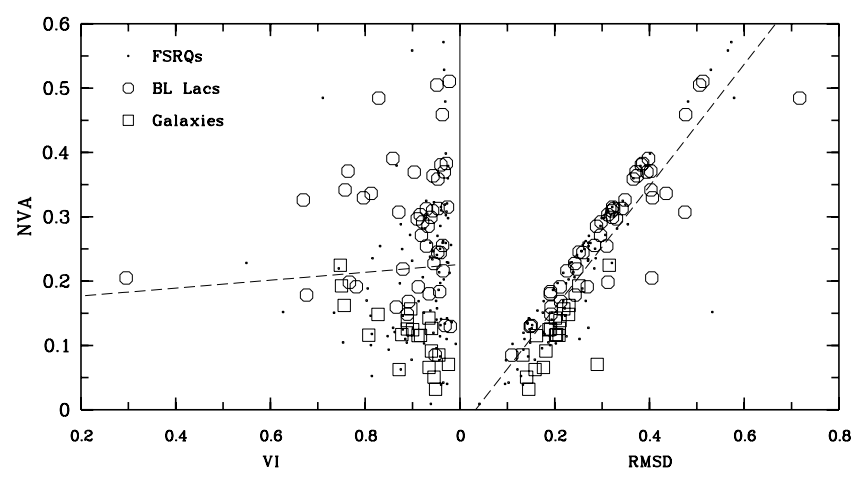

Fig. 3. Correlation between variability parameters. Left panel is for NVA and VI, while the right panel is for NVA and RMSD.

\subsection{Periodicity in the radio light curves: individual source}

The long-term variability period analysis was done at other wavebands for some sources in the literature. Here we compare the radio results with published optical and other EM band results.

\subsubsection{PKS $0219+428(3 \mathrm{C} 66 \mathrm{~A})$}

In optical bands, a 65-day period was reported by Lainela et al. (1999). Long-term variability periods of 2.5 years (Belokon \& Babadzhanyants 2003) and $4.25 \pm 0.28$ years (Fan et al. 2002a) were reported. In the present paper, no possible period can be found in the period analysis of the radio light curves.

\subsection{2. $\mathrm{AO} 0235+164$}

A possible periodicity of $\sim 5.7$ years was reported in the radio light curve by Roy et al. (2000) and Raiteri et al. (2001). Our result shows that there is a period of $5.7 \pm 0.3$ years in $8 \mathrm{GHz}$ with $F A P=0.452$ and $5.8 \pm 0.3$ years in $14.5 \mathrm{GHz}$ with $F A P=$ 0.436 , which are quite consistent with the earlier result. 
Table 4. Correlation between variability parameter and flux density, Vari $=a \log F_{8 \mathrm{GHz}}+b$.

\begin{tabular}{lccc}
\hline \hline Param. & $a \pm \Delta a$ & $b \pm \Delta b$ & $r$ \\
$(1)$ & $(2)$ & $(3)$ & $(4)$ \\
\hline $\log F_{8 \mathrm{GHz}}-R M S D$ & $-0.04 \pm 0.02$ & $2.27 \pm 0.01$ & -0.17 \\
$\log F_{8 \mathrm{GHz}}-N V A$ & $0.01 \pm 0.02$ & $1.41 \pm 0.01$ & 0.05 \\
$\log F_{8 \mathrm{GHz}}-V I$ & $0.132 \pm 0.01$ & $0.88 \pm 5.7 \times 10^{-3}$ & 0.65 \\
\hline
\end{tabular}

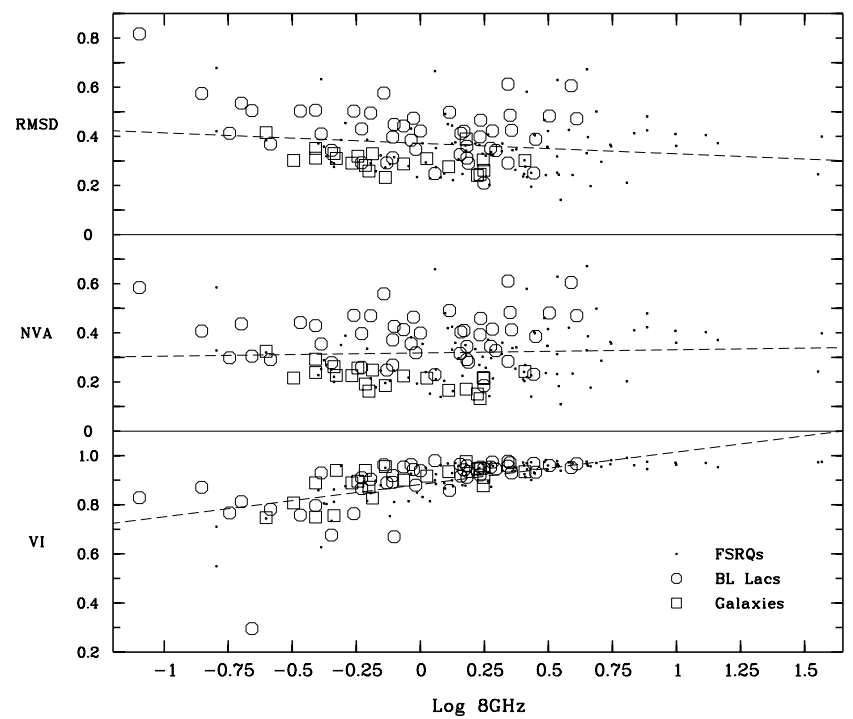

Fig. 4. Correlation between the variability parameter and radio brightness (averaged flux density). The upper panel indicates the relation between RMSD and the $8 \mathrm{GHz}$ flux density, the middle panel indicates the relation between NVA and the $8 \mathrm{GHz}$ flux density, and the lower panel indicates the relation between V.I. and the $8 \mathrm{GHz}$ flux density. The lines show the best fitting results mentioned in the text.

\subsubsection{S5 $0716+714$}

A periodicity of 5.5-6 years was found in the radio emission by Raiteri et al. (2003). Our result shows periods of $5.7 \pm 0.5$ years in $4.8 \mathrm{GHz}$ with $F A P=0.200$ and $5.4 \pm 0.3$ years in $14.5 \mathrm{GHz}$ with $F A P=0.117$, which are consistent with the earlier result.

\subsubsection{PKS $0735+178$}

We report periods of 4.89 and 14.2 years in the optical band (Fan et al. 1997). The period of 4.89 years was also found by Webb et al. (1988). For the radio data, a period of $13.5 \pm 0.9$ years in $14.5 \mathrm{GHz}$ with $F A P=0.003$ and possible periods of $12.9 \pm$ 0.9 years in $4.8 \mathrm{GHz}$ with $F A P=0.002$ and $15.0 \pm 1.2$ years in $8 \mathrm{GHz}$ with $F A P=0.011$ were found, which are quite consistent with the 14.2-year optical period.

\subsubsection{PKS $0754+100$}

The periods of $3.0 \pm 0.35$ and 17.85 years were found in our earlier paper (Fan et al. 2002a). In the present paper, periods of $6.6 \pm 0.7$ years in $4.8 \mathrm{GHz}$ with $F A P=0.222$ and $6.8 \pm 0.6$ years in $14.5 \mathrm{GHz}$ with $F A P=0.278,11.8 \pm 2.3$ years in $4.8 \mathrm{GHz}$ with $F A P=0.182,10.4 \pm 0.8$ years in $8 \mathrm{GHz}$ with $F A P=0.014$, $11.3 \pm 1.0$ years in $14.5 \mathrm{GHz}$ with $F A P=0.015$, and a possible period of $15.0 \pm 3.6$ years in $4.8 \mathrm{GHz}$ with $F A P=0.167$ were also found. The $15.0 \pm 3.6$ year possible period is consistent with the optical result, 17.85 years.

\subsubsection{PKS $0851+202$ (OJ 287)}

Sillanpaa et al. (1988) reported a 11.65 -year period in the optical light curve. Periods of $5.53 \pm 0.15$ and $11.75 \pm 0.5$ years were reported in our earlier paper (Fan et al. 2002a). But the radio light curve shows periods of $8.8 \pm 1.0$ years in $4.8 \mathrm{GHz}$ with $F A P=0.445$ and $9.4 \pm 0.6$ years in $8 \mathrm{GHz}$ with $F A P=0.266$, which is very different from the previously reported optical periods.

\subsubsection{PKS 1219+285}

A $14.85 \pm 1.55$ year period was found in the optical band (Fan et al. 2002a). The present result shows a period of $10.4 \pm$ 1.4 years in $8 \mathrm{GHz}$ with $F A P=0.293$ and $10.0 \pm 1.4$ years in $14.5 \mathrm{GHz}$ with $F A P=0.306$.

\subsubsection{PKS 1226+023 (3C 273)}

Periods of 2.0 years and $13.65 \pm 0.2$ years were reported in the optical band. A possible period of 13.5 years was reported in the X-ray band by Manchanda (2002). The present work gives periods of $8.8 \pm 0.3$ years in $4.8 \mathrm{GHz}$ with $F A P=0.001,8.3 \pm$ 0.2 years in $8 \mathrm{GHz}$ with $F A P=0.006$, and $8.2 \pm 0.2$ years in $14.5 \mathrm{GHz}$ with $F A P=0.001$.

\subsubsection{PKS 1253-055 (3C 279)}

The infrared light curve shows a period of $7.1 \pm 0.44$ years (Fan 1999). The present work shows periods of $5.1 \pm 0.2$ years with $F A P=0.357,7.4 \pm 0.3$ years with $F A P=0.307,10.1 \pm 0.7$ years with $F A P=0.426$, and $15.1 \pm 1.5$ years with $F A P=0.352$ in $8.0 \mathrm{GHz}$. The $7.4 \pm 0.3$ year period is quite consistent with what is found in the infrared band.

\subsubsection{PKS 2155-304}

Based on the optical light curves, periodicity of 4.6 and 7.0 years was reported (Fan \& Lin 2000). In the present paper, no possible period was found by power spectral analysis.

\subsubsection{PKS 2200+420 (BL Lacertae)}

The optical periodicity was analyzed and found to be 14.0 years (Fan et al. 1998). The present work reports periods of $3.9 \pm$ 0.2 years in $4.8 \mathrm{GHz}$ with $F A P=0.471,3.8 \pm 0.1$ years in $8 \mathrm{GHz}$ with $F A P=0.189,3.9 \pm 0.1$ years in $14.5 \mathrm{GHz}$ with $F A P=0.350,7.8 \pm 0.4$ years in $4.8 \mathrm{GHz}$ with $F A P=0.021$, $6.8 \pm 0.3$ years in $8 \mathrm{GHz}$ with $F A P=0.332$, and $7.8 \pm 0.4$ years in $14.5 \mathrm{GHz}$ with $F A P=0.118$.

\section{Discussions and conclusions}

Blazars are variable over all electromagnetic wavelengths. Optical photometry is available for some blazars for about a century (Fan 2005a). The radio monitoring program started much too late, only about 40 years ago. But the radio monitoring coverage is also long enough for the periodicity analysis and the variability property investigations.

There are 168 radio sources in the UMRAO data base, and the observation time coverage of the radio light curves is from 0.1 year for $1217+023$ to 33.8 years for $1226+023$ (3C 273). When the power spectral periodicity analysis method 
was adopted to the $4.8 \mathrm{GHz}, 8.0 \mathrm{GHZ}$, and $14.5 \mathrm{GHz}$ light curves for the 168 sources, 203 astrophysically meaningful periods $\left(F A P<0.50\right.$ and Tms $\left.<\frac{2}{3} \mathrm{ObT}\right)$ were obtained for 66 sources (see Table 1). The periods are different from one source to another, which is from 2.2 years for $0454-234$ at $4.8 \mathrm{GHz}$ to $20.8 \pm$ 1.2 years for $1641+399$ at $8.0 \mathrm{GHz}$. There is no clear possible period sign found for the other 102 sources for which either the FAP is greater than 0.5 for the period or the period is $2 / 3$ times longer than the observation time coverage (see Table 1, the superscript " $F$ " means the period is not a physically meaningful one $(F A P>0.5$ or Tms $>\mathrm{ObT})$, and the superscript "P" means it is a possible time scale $(F A P<0.5$ and $2 / 3 \mathrm{ObT}<\mathrm{Tms}<\mathrm{ObT})$ ). Here, we take the periods with $F A P>0.5$ to have no physical meaning. In addition, if the determined period is $2 / 3$ times longer than the observation time coverage, we did not take it as a physically meaningful period either. It can be mentioned that from data that is pure noise, any method of period estimation will yield some false probabilities in the period range that is roughly equal to the length of the data samples, or somewhat smaller.

If we consider galaxie, FSRQs and BLs separately, we find that the physically significant periodicity at $8 \mathrm{GHz}$ are in the range of 2.2 to 20.8 years for FSRQs (55 physically meaningful periods for 34 objects) and from 2.5 to 18.0 years for BLs (27 physically meaningful periods for 17 objects). However, there is no physically significant periodicity found for galaxies. The average value of the periodicity is $8.9 \pm 4.0$ years for FSRQs and $8.1 \pm 3.4$ years for BLs. In Table 2 and Fig. 4, we can see that RMSD and NVA for galaxies are lower than those for FSRQs and BLs. It is interesting that the sources with physically meaningful periods have higher RMSD and NVA.

Our results are also consistent with the results obtained by Ciaramella et al. (2004), who have analyzed the periodicity from the high-frequency radio data. The physically meaningful period histogram at $8 \mathrm{GHz}$ for the subclass samples of BLs and FSRQs are shown in Fig. 5. There is no clear difference in the possible periodicity distribution as shown in Fig. 6, in which the Kolmogorov-Smirnov (K-S) test indicates that the probability for the possible periodicity distributions of BL Lac objects and FSRQs coming from the same parent distribution is greater than $68.2 \%$. If the possible periodicity is associated with the central structure, namely associated with the central blackhole mass, then the similar possible periodicity distribution for FSRQs and BLs should suggest that their central black-hole masses show a similar distribution. In fact, no clear difference was found in the central black-hole masses of BLs and FSRQs (Fan 2005b).

From the sources listed in Sect. 4.1, we can see that the periods found in the optical bands were not always consistent with those found in the radio bands. Some sources show similar radio and optical variability periods: $0735+178$ show a significant radio period of $13.5 \pm 0.9$ years and two possible radio periods of $12.9 \pm 0.9$ and $15.0 \pm 1.2$, and an optical period of 14.2 years, $0754+100$ shows a possible radio period of $15.0 \pm 3.6$ years and an optical period of 17.85 years, $1253-055$ shows radio periods of 7.1 to 7.4 years and an infrared period of $7.1 \pm 0.44$ years for instance. Meanwhile some others show different possible periods (OJ 287, 1226+023(3C 273), 2200+420 for instance. This difference is perhaps from the fact that the light curves used for the possible periodicity analysis were not long enough in some sources, or the variation in the radio bands and optical bands were caused by different mechanisms as noticed in the case of OJ 287, and the observed optical outbursts were not correlated with those observed in the radio band (Takalo 1998). For some

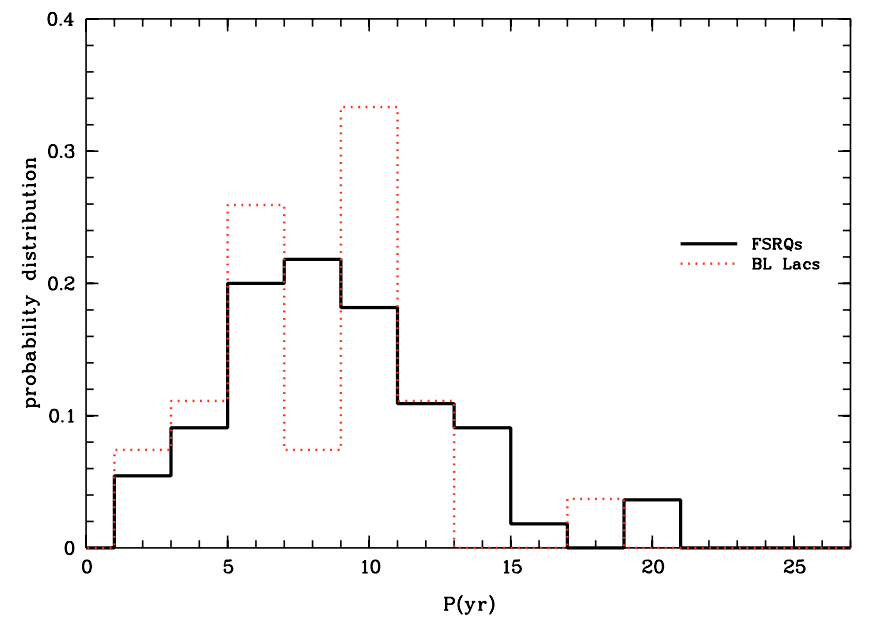

Fig. 5. Histogram of the periodicity, $P$ (in units of years) at $8 \mathrm{GHz}$ for BL Lacertae objects and FSRQs. The dotted line stands for BLs and the filled line for FSRQs.

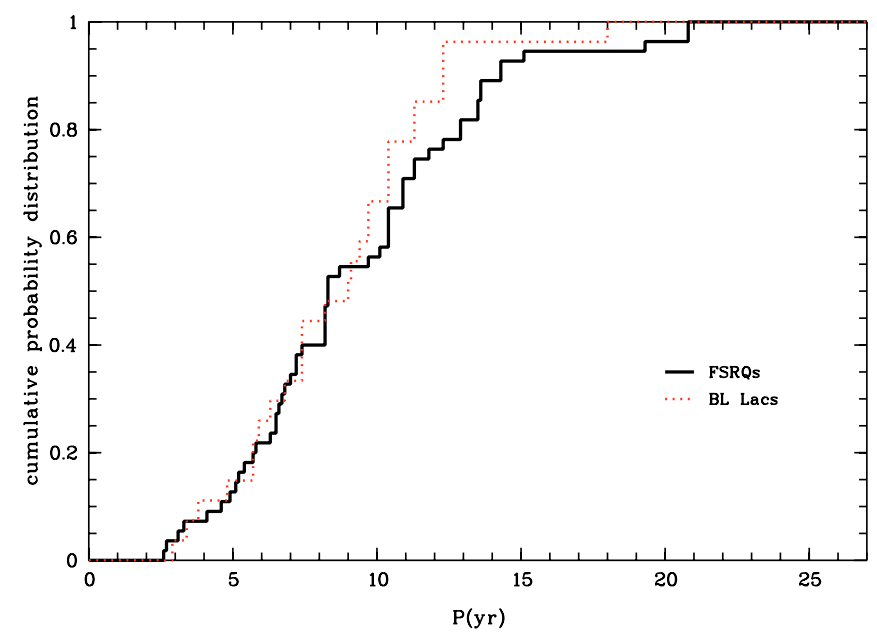

Fig. 6. Accumulative results for the periodicity (in units of years) at $8 \mathrm{GHz}$ for BL Lacertae objects and FSRQs. The dotted line stands for BLs and filled line for FSRQs.The Kolmogorov-Smirnov test indicates that the probability for the possible periodicity distributions of BL Lac objects and FSRQs coming from the same parent distribution is $68.2 \%$.

cases, it is possible that the lack of agreement between optical and radio possible periods is due to the fact that one or the other is spurious, just due to noise.

For AGNs, the variability mechanism is not yet well understood. Some models have been proposed to explain the optical long-term possible periodic variations: the binary black-hole model, the thermal instability model, and the perturbation model (Fan 2005a). The promising models are the binary black-hole model and the perturbation model. The helical jet related with the binary black holes have been used to explain the optical variability behavior for the objects (3C 345, OJ 287, BL Lacertae, and PKS 0735+178). It has been claimed that the possible periodicity in the historical light curves also show helical trajectories in their VLBI radio components (Villata \& Raiteri 1999). In this sense, one would expect similar possible periodicity behavior in optical and radio bands, which has been confirmed for many sources in our analysis. In the radio bands, the variability is explained by various mechanisms (Ciaramella et al. 2004) such as shocks in jets, changes in the direction of forward 
beaming, and precession in a binary black-hole system (Marscher \& Gear 1985; Aller et al. 1985; Camenzind \& Krockenberger 1992; Begelman et al. 1980; Rieger \& Mannheim 2000, 2003).

The variability parameters viz. variability index VI, normalized variability amplitude NVA, and RMSD are listed in the Table 2, in which $W$ stands for the whole sample. These parameters show that the sources are variable, and NVA and RMSD are correlated. On the other hand, no correlation was found in the VI parameter with NVA or RMSD (see Table 3, Fig. 3). This suggests that NVA and RMSD are more reliable for the variability indication than the VI. Therefore, we suggest using NVA and RMSD for indicating variability violence, if possible. It is also easily found that the variability parameter at higher frequency is greater than those in the lower frequency.

However, for the correlation between the variability parameter and the flux density, we found that the relationship between the source brightness and NVA and/or RMSD is not as close as the one between the source flux density and VI (see Fig. 4 and Table 4). We think that the correlation between the source brightness and VI is an apparent result, since the VI and the brightness (namely the averaged flux density) are more associated with the maximum flux density when the difference between the maximum and the minimum is big enough, which will result in an apparent correlation. Therefore, we do not think that there is a correlation between the brightness and the variability in the radio bands.

When we considered BLs and FSRQs separately, we found that the NVA and RMSD of BLs are larger than those of FSRQs, and the NVA and RMSD of BLs and FSRQs are larger than those of galaxies. This finding suggests that BLs are more variable than FSRQs in the radio bands. In addition, there is a tendency for the variability parameter to increase with the frequency for the whole sample and the individual BLs and FSRQ sub-samples. This tendency is also found in the optical bands.

In the present paper, the power spectral (Fourier) periodicity analysis method was adopted to a large sample of radio sources given in UMRAO. The results show that the possible periodicity is present in the range of 2.2 to 20.8 years for 66 radio sources. BLs are more variable than FSRQs and the variability parameters depend on the frequency.

Acknowledgements. The authors thank the referee for the constructive comments and suggestions. This work is partially supported by the National 973 project (NKBRSF G19990754), the National Science Fund for Distinguished Young Scholars (10125313), the National Natural Science Foundation of China
(10573005, 10633010), and the Fund for Top Scholars of Guangdong Province (Q02114). We also thank the financial support from the Guangzhou Education Bureau and Guangzhou Science and Technology Bureau. ACG's efforts are partially supported by the Department of Atomic Energy, Govt. of India. This research made use of data from the University of Michigan Radio Astronomy Observatory, which is supported by the University of Michigan and the National Science Foundation.

\section{References}

Aller, H. D., Aller, M. F., \& Hughes, P. A. 1985, ApJ, 298, 296 Aller, M. F., Aller, H. D., \& Hughes, P. A. 1992, ApJ, 399, 16 Aller, M. F., Aller, H. D., \& Hughes, P. A. 2003, ApJ, 586, 33 Begelman, M. C., Blandford, R. D., \& Rees, M. J. 1980, Nature, 287, 307 Belokon, E. T., \& Babadzhanyants, M. K. 2003, Heba. Conf., 205 Bondi, M., Padrielli, L., Fanti, R., et al. 1996, A\&AS, 120, 89 Camenzind, M., \& Krockenberger, M. 1992, A\&A, 255, 59 Ciaramella, A., Bongardo, C., Aller, H. D., et al. 2004, A\&A, 419, 485 Edelson, R. P., et al. 1992, ApJS, 83, 1

Edelson, R. A., Alexander, T., Crenshaw, D. M., et al. 1996, ApJ, 470, 364 Fan, J. H. 2005a, ChJAA, 5S, 213

Fan, J. H. 2005b, A\&A, 436, 799

Fan, J. H., \& Lin, R. G. 2000, A\&A, 355, 880

Fan, J. H., Lin, R. G., Xie, G. Z., et al. 2002a, A\&A, 381, 1

Fan, J. H., Cheng, K. S., \& Zhang, L. 2002b, PASJ, 54, No. 4, 533 Fan, J. H. 1999, MNRAS, 308, 1032

Fan, J. H., Xie, G. Z., Pecontal, E., et al. 1998, ApJ, 507, 178

Fan, J. H., Xie, G. Z., \& Lin, R. G. 1997, A\&AS, 125, 525 Ferraz-Mello, S. 1981, AJ, 86, 619

Foster, G. 1995, AJ, 109, 1889

Horne, J., \& Baliunas, S. 1986, ApJ, 302, 757

Jurkevich, I. 1971, Ap\&SS, 13, 154

Kembhavi, A. K., \& Narlika, J. V. 1999, Quasars and Active Galactic Nuclei (Cambridge Uni. Press)

Kidger, M. R., Takalo, L., \& Sillanpaa, A. 1992, A\&A, 264, 32

Kraus, A., Quirrenbach, A., Lobanov, A. P., et al. 1999, A\&A, 344, 807

Lahteenmaki, A., \& Valtaoja, E. 1999, ApJ, 521, 493

Lainela, M., Takalo, L. O., Sillanpaa, A., et al. 1999, ApJ, 521, 561

Manchanda, K. R. 2002, JApA, 23, 243

Marscher, A. P., \& Gear, W. K. 1985, ApJ, 298, 114

Raiteri, C. M., Villata, M., Aller, H. D., et al. 2001, A\&A, 337, 396

Raiteri, C. M., Villata, M., Tosti, G., et al. 2003, A\&A, 402, 151

Rieger, F. M., \& Mannheim, K. 2000, A\&A, 359, 948

Rieger, F. M., \& Mannheim, K. 2003, A\&A, 397, 121

Romero, G. E., et al. 1999, A\&AS, 135, 477

Roy, M., Papadakis, I. E., Ramos-Colon, E., Sambruna, R., et al. 2000, ApJ, 545, 758

Scargle, J. 1982, ApJ, 263, 835

Sillanpaa, A., Haarala, S., Valtonen, M. J., Sundelius, B., \& Byrd, G. G. 1988, ApJ, 325, 628

Takalo, L. O. 1998, A\&AS, 129, 577

Tornikoski, M., Valtaoja, E., Teräsranta, H., et al. 1996, A\&AS, 116, 157

Villata, M., \& Raiteri, C. M. 1999, A\&A, 347, 30

Webb, J. R., Smith, A. G., Leacock, R. J., et al. 1988, AJ, 95, 374 


\section{Online Material}


J. H. Fan et al.: Radio variability properties for radio sources, Online Material $p 2$

Table 1. Periodicity results and the variability parameters of radio galaxies. Designation indicates the name of the source, Freq the frequency in units of $\mathrm{GHz}, \delta_{N}$ the root mean square deviation, the $\delta_{N}^{2}$ is the total variance of data; $A$ - the amplitude, FAP - the false alarm probability of the determined possible period, Tms - the determined possible period in units of years, ObT - the time coverage of the light curve in units of years, $N$ - the number of data points, VI - VI index, NVA - NVA index, RMSD - RMSD index, ID - source identification (B for BL Lacertae, Q for the flat spectrum radio quasar and $\mathrm{G}$ for galaxy). The superscript " $\mathrm{F}$ " means it is not a physically meaningful period $(F A P>0.5 \mathrm{or}$ Tms $>\mathrm{ObT})$, and the superscript "P" means it is a possible time scale $\left(F A P<0.5\right.$ and $\left.\frac{2}{3} \mathrm{ObT}<\mathrm{Tms}<\mathrm{ObT}\right)$.

\begin{tabular}{|c|c|c|c|c|c|c|c|c|c|c|c|}
\hline Designation & Freq & $\delta_{N}$ & A & Fap & Tms & ObT & $N$ & VI & NVA & RMSD & ID \\
\hline \multirow[t]{3}{*}{ 0003-066 } & 048 & 0.495 & 0.650 & 0.005 & $17.9 \pm 3.1^{F}$ & 16.7 & 70 & & & & \\
\hline & & 0.495 & 0.648 & 0.006 & $9.0 \pm 0.8$ & 16.7 & 70 & & & & \\
\hline & & 0.495 & 0.548 & 0.113 & $5.3 \pm 0.5$ & 16.7 & 70 & & & & \\
\hline \multirow{3}{*}{ 0003-066 } & 080 & 0.782 & 1.052 & 0.001 & $20.6 \pm 2.1^{F}$ & 19.7 & 131 & 0.93 & 0.31 & 0.32 & B \\
\hline & & 0.782 & 0.919 & 0.018 & $9.7 \pm 0.9$ & 19.7 & 131 & & & & \\
\hline & & 0.782 & 0.716 & 0.418 & $5.7 \pm 0.6$ & 19.7 & 131 & & & & \\
\hline \multirow{4}{*}{ 0003-066 } & 145 & 0.739 & 0.997 & 0.002 & $29.4 \pm 5.2^{F}$ & 17.5 & 102 & & & & \\
\hline & & 0.739 & 0.880 & 0.020 & $9.3 \pm 1.1$ & 17.5 & 102 & & & & \\
\hline & & 0.739 & 0.687 & 0.484 & $7.3 \pm 1.2$ & 17.5 & 102 & & & & \\
\hline & & 0.739 & 0.701 & 0.409 & $4.9 \pm 0.5$ & 17.5 & 102 & & & & \\
\hline \multirow[t]{7}{*}{$0007+106$} & 048 & 0.307 & 0.372 & 0.015 & $925.8 \pm 9257.1^{F}$ & 18.5 & 101 & & & & \\
\hline & & 0.307 & 0.363 & 0.023 & $10.4 \pm 1.3$ & 18.5 & 101 & & & & \\
\hline & & 0.307 & 0.302 & 0.302 & $7.2 \pm 1.0$ & 18.5 & 101 & & & & \\
\hline & & 0.307 & 0.378 & 0.011 & $5.0 \pm 0.2$ & 18.5 & 101 & & & & \\
\hline & & 0.307 & 0.298 & 0.339 & $3.8 \pm 0.3$ & 18.5 & 101 & & & & \\
\hline & & 0.307 & 0.332 & 0.093 & $3.2 \pm 0.2$ & 18.5 & 101 & & & & \\
\hline & & 0.307 & 0.314 & 0.197 & $2.3 \pm 0.1$ & 18.5 & 101 & & & & \\
\hline \multirow[t]{5}{*}{$0007+106$} & 080 & 0.509 & 0.450 & 0.163 & $64.7 \pm 40.8^{F}$ & 23.1 & 341 & 0.90 & 0.56 & 0.57 & Q \\
\hline & & 0.509 & 0.449 & 0.165 & $11.8 \pm 1.4$ & 23.1 & 341 & & & & \\
\hline & & 0.509 & 0.494 & 0.063 & $7.4 \pm 0.4$ & 23.1 & 341 & & & & \\
\hline & & 0.509 & 0.532 & 0.025 & $5.2 \pm 0.2$ & 23.1 & 341 & & & & \\
\hline & & 0.509 & 0.488 & 0.072 & $4.1 \pm 0.1$ & 23.1 & 341 & & & & \\
\hline \multirow[t]{2}{*}{$0007+106$} & 145 & 0.615 & 0.546 & 0.185 & $5.0 \pm 0.3$ & 21.0 & 301 & & & & \\
\hline & & 0.615 & 0.549 & 0.175 & $4.1 \pm 0.2$ & 21.0 & 301 & & & & \\
\hline $0016+731$ & 048 & 0.300 & 0.319 & 0.044 & $777.7 \pm 8011.9^{F}$ & 15.6 & 201 & & & & \\
\hline \multirow[t]{2}{*}{$0016+731$} & 080 & 0.455 & 0.475 & 0.111 & $81.5 \pm 118.3^{F}$ & 15.2 & 127 & 0.93 & 0.32 & 0.34 & Q \\
\hline & & 0.455 & 0.429 & 0.337 & $6.6 \pm 1.0$ & 15.2 & 127 & & & & \\
\hline \multirow[t]{2}{*}{$0016+731$} & 145 & 0.446 & 0.408 & 0.217 & $32.8 \pm 18.3^{F}$ & 15.5 & 219 & & & & \\
\hline & & 0.446 & 0.455 & 0.066 & $6.6 \pm 0.6$ & 15.5 & 219 & & & & \\
\hline $0022+638$ & 048 & 0.292 & 0.150 & 1.000 & $0.1 \pm 0.0^{F}$ & 15.9 & 68 & & & & \\
\hline $0022+638$ & 080 & 0.368 & 0.279 & 1.000 & $0.1 \pm 0.0^{F}$ & 15.3 & 48 & * & * & * & \\
\hline $0022+638$ & 145 & 0.160 & 0.115 & 1.000 & $0.3 \pm 0.0^{F}$ & 15.4 & 59 & & & & \\
\hline $0040+517$ & 048 & 0.126 & 0.079 & 1.000 & $0.2 \pm 0.0^{F}$ & 14.2 & 54 & & & & \\
\hline $0040+517$ & 080 & 0.182 & 0.127 & 1.000 & $0.1 \pm 0.0^{F}$ & 14.0 & 40 & 0.93 & 0.07 & 0.18 & G \\
\hline $0040+517$ & 145 & 0.106 & 0.060 & 1.000 & $0.3 \pm 0.0^{F}$ & 14.3 & 83 & & & & \\
\hline
\end{tabular}


J. H. Fan et al.: Radio variability properties for radio sources, Online Material $p 3$

Table 1. continued.

\begin{tabular}{|c|c|c|c|c|c|c|c|c|c|c|c|}
\hline Designation & Freq & $\delta_{N}$ & $\mathrm{~A}$ & Fap & Tms & ObT & $\bar{N}$ & VI & NVA & $\overline{\mathrm{RMSD}}$ & ID \\
\hline 0048-097 & 048 & 0.260 & 0.166 & 0.999 & $33.0 \pm 32.3^{F}$ & 18.5 & 144 & & & & \\
\hline 0048-097 & 080 & 0.446 & 0.408 & 0.103 & $125.2 \pm 109.4^{F}$ & 29.1 & 372 & 0.92 & 0.30 & 0.31 & B \\
\hline 0048-097 & 145 & 0.459 & 0.343 & 0.589 & $16.8 \pm 4.4^{F}$ & 19.6 & 304 & & & & \\
\hline $0059+581$ & 048 & 0.339 & 0.312 & 0.988 & $0.5 \pm 0.1^{F}$ & 4.2 & 27 & & & & \\
\hline $0059+581$ & 080 & 0.281 & 0.231 & 1.000 & $3.4 \pm 2.4^{F}$ & 3.9 & 35 & 0.92 & 0.10 & 0.20 & $\mathrm{Q}$ \\
\hline \multirow[t]{2}{*}{$0059+581$} & 145 & 0.876 & 1.125 & 0.008 & $3.4 \pm 0.4^{P}$ & 4.8 & 69 & & & & \\
\hline & & 0.876 & 1.101 & 0.013 & $1.8 \pm 0.1$ & 4.8 & 69 & & & & \\
\hline $0106+013$ & 048 & 1.121 & 1.502 & 0.002 & $22.2 \pm 3.4^{F}$ & 15.9 & 105 & \multirow{3}{*}{0.93} & \multirow{3}{*}{0.30} & \multirow{3}{*}{0.30} & \multirow{3}{*}{ Q } \\
\hline $0106+013$ & 080 & 1.134 & 1.490 & 0.001 & $24.4 \pm 2.1^{F}$ & 21.9 & 284 & & & & \\
\hline $0106+013$ & 145 & 1.091 & 1.410 & 0.001 & $26.8 \pm 3.0^{F}$ & 24.4 & 209 & & & & \\
\hline $0108+388$ & 048 & 0.096 & 0.057 & 1.000 & $0.2 \pm 0.0^{F}$ & 15.5 & 66 & \multirow{3}{*}{0.86} & \multirow{3}{*}{0.12} & \multirow{3}{*}{0.18} & \multirow{3}{*}{ Q } \\
\hline $0108+388$ & 080 & 0.135 & 0.060 & 1.000 & $0.1 \pm 0.0^{F}$ & 15.0 & 97 & & & & \\
\hline $0108+388$ & 145 & 0.047 & 0.030 & 1.000 & $0.2 \pm 0.0^{F}$ & 15.5 & 63 & & & & \\
\hline $0109+224$ & 048 & 0.189 & 0.180 & 0.432 & $83.3 \pm 138.6^{F}$ & 18.9 & 92 & \multirow{3}{*}{0.90} & \multirow{3}{*}{0.37} & \multirow{3}{*}{0.39} & \multirow{3}{*}{ B } \\
\hline $0109+224$ & 080 & 0.236 & 0.218 & 0.412 & $52.1 \pm 45.0^{F}$ & 20.9 & 124 & & & & \\
\hline $0109+224$ & 145 & 0.249 & 0.243 & 0.242 & $37.6 \pm 22.6^{F}$ & 19.6 & 123 & & & & \\
\hline $0127+233$ & 048 & 0.100 & 0.059 & 1.000 & $0.1 \pm 0.0^{F}$ & 16.7 & 59 & \multirow{3}{*}{0.73} & \multirow{3}{*}{0.15} & \multirow{3}{*}{0.19} & \multirow{3}{*}{ Q } \\
\hline $0127+233$ & 080 & 0.135 & 0.062 & 1.000 & $0.2 \pm 0.0^{F}$ & 16.6 & 129 & & & & \\
\hline $0127+233$ & 145 & 0.056 & 0.043 & 0.999 & $16.8 \pm 10.5^{F}$ & 16.5 & 69 & & & & \\
\hline $0133+476$ & 048 & 0.367 & 0.398 & 0.010 & $9.0 \pm 0.6$ & 19.2 & 446 & \multirow{6}{*}{0.94} & \multirow{6}{*}{0.24} & \multirow{6}{*}{0.24} & \multirow{6}{*}{ Q } \\
\hline $0133+476$ & 080 & 0.527 & 0.513 & 0.021 & $124.8 \pm 75.0^{F}$ & 28.0 & 678 & & & & \\
\hline \multirow{4}{*}{$0133+476$} & & 0.527 & 0.341 & 0.455 & $10.9 \pm 1.0$ & 28.0 & 678 & & & & \\
\hline & & 0.527 & 0.377 & 0.286 & $5.8 \pm 0.3$ & 28.0 & 678 & & & & \\
\hline & 145 & 0.574 & 0.546 & 0.036 & $1227.0 \pm 9467.1^{F}$ & 24.5 & 563 & & & & \\
\hline & & 0.574 & 0.517 & 0.066 & $10.4 \pm 0.8$ & 24.5 & 563 & & & & \\
\hline $0134+329$ & 048 & 0.225 & 0.211 & 0.982 & $0.3 \pm 0.0^{F}$ & 7.5 & 25 & \multirow{3}{*}{0.96} & \multirow{3}{*}{0.04} & & \\
\hline $0134+329$ & 080 & 0.166 & 0.130 & 0.928 & $22.4 \pm 8.6^{F}$ & 26.9 & 121 & & & 0.10 & Q \\
\hline $0134+329$ & 145 & 0.112 & 0.073 & 1.000 & $0.3 \pm 0.0^{F}$ & 17.8 & 77 & & & & \\
\hline $0153+744$ & 048 & 0.140 & 0.155 & 0.098 & $37.1 \pm 29.1^{F}$ & 14.2 & 77 & & & & \\
\hline $0153+744$ & 080 & 0.279 & 0.274 & 0.844 & $0.1 \pm 0.0^{F}$ & 13.7 & 31 & 0.88 & 0.29 & 0.35 & Q \\
\hline $0153+744$ & 145 & 0.091 & 0.083 & 0.685 & $725.1 \pm 15642.3^{F}$ & 14.5 & 87 & & & & \\
\hline $0202+149$ & 048 & 0.419 & 0.461 & 0.046 & $12.8 \pm 2.3^{P}$ & 16.5 & 138 & & & & \\
\hline $0202+149$ & 080 & 0.381 & 0.353 & 0.107 & $12.9 \pm 1.8$ & 19.5 & 328 & 0.94 & 0.12 & 0.13 & Q \\
\hline $0202+149$ & 145 & 0.451 & 0.437 & 0.112 & $13.5 \pm 2.2^{P}$ & 19.1 & 234 & & & & \\
\hline $0212+735$ & 048 & 0.357 & 0.483 & 0.001 & $26.5 \pm 3.2^{F}$ & 15.5 & 204 & & & & \\
\hline $0212+735$ & 080 & 0.347 & 0.370 & 0.049 & $24.2 \pm 6.9^{F}$ & 18.1 & 186 & 0.90 & 0.13 & 0.15 & Q \\
\hline $0212+735$ & 145 & 0.456 & 0.512 & 0.014 & $15.0 \pm 2.0^{P}$ & 18.1 & 249 & & & & \\
\hline
\end{tabular}


J. H. Fan et al.: Radio variability properties for radio sources, Online Material $p 4$

Table 1. continued.

\begin{tabular}{|c|c|c|c|c|c|c|c|c|c|c|c|}
\hline Designation & Freq & $\delta_{N}$ & A & Fap & Tms & ObT & $N$ & VI & NVA & RMSD & ID \\
\hline $0215+015$ & 048 & 0.253 & 0.216 & 0.871 & $15.8 \pm 6.6^{F}$ & 18.1 & 85 & & & & \\
\hline \multirow[t]{2}{*}{$0215+015$} & 080 & 0.375 & 0.334 & 0.324 & $15.0 \pm 3.3^{P}$ & 19.6 & 198 & 0.96 & 0.24 & 0.26 & B \\
\hline & & 0.375 & 0.341 & 0.270 & $3.4 \pm 0.2$ & 19.6 & 198 & & & & \\
\hline $0215+015$ & 145 & 0.454 & 0.406 & 0.436 & $3.6 \pm 0.2$ & 19.6 & 149 & & & & \\
\hline $0218+357$ & 048 & 0.080 & 0.066 & 1.000 & $4.0 \pm 2.3^{F}$ & 6.4 & 27 & & & & \\
\hline $0218+357$ & 080 & 0.158 & 0.153 & 0.961 & $336.5 \pm 12790.9^{F}$ & 6.7 & 22 & 0.88 & 0.11 & 0.25 & Q \\
\hline $0218+357$ & 145 & 0.139 & 0.113 & 0.904 & $6.7 \pm 4.1^{F}$ & 5.0 & 108 & & & & \\
\hline $0219+428$ & 048 & 0.257 & 0.315 & 0.014 & $33.0 \pm 11.6^{F}$ & 18.8 & 93 & & & & \\
\hline \multirow[t]{2}{*}{$0219+428$} & 080 & 0.166 & 0.170 & 0.242 & $1218.4 \pm 21110.3^{F}$ & 24.4 & 83 & 0.89 & 0.17 & 0.21 & B \\
\hline & & 0.166 & 0.172 & 0.217 & $29.7 \pm 12.3^{F}$ & 24.4 & 83 & & & & \\
\hline $0219+428$ & 145 & 0.248 & 0.308 & 0.009 & $26.7 \pm 6.4^{F}$ & 19.6 & 108 & & & & \\
\hline $0220+427$ & 048 & 0.131 & 0.085 & 1.000 & $0.2 \pm 0.0^{F}$ & 15.7 & 53 & \multirow{3}{*}{0.90} & \multirow{3}{*}{0.12} & \multirow{3}{*}{0.19} & \multirow{3}{*}{ G } \\
\hline $0220+427$ & 080 & 0.235 & 0.268 & 0.096 & $1452.5 \pm 23780.4^{F}$ & 29.0 & 55 & & & & \\
\hline $0220+427$ & 145 & 0.156 & 0.159 & 0.398 & $811.9 \pm 17372.2^{F}$ & 16.2 & 55 & & & & \\
\hline $0234+285$ & 048 & 0.825 & 1.037 & 0.003 & $15.0 \pm 1.6^{P}$ & 17.4 & 190 & \multirow{3}{*}{0.97} & \multirow{3}{*}{0.36} & \multirow{3}{*}{0.37} & \multirow{3}{*}{ Q } \\
\hline $0234+285$ & 080 & 1.275 & 1.737 & 0.000 & $17.9 \pm 1.3^{F}$ & 15.8 & 217 & & & & \\
\hline $0234+285$ & 145 & 1.052 & 1.333 & 0.002 & $19.1 \pm 2.5^{F}$ & 15.8 & 238 & & & & \\
\hline $0235+164$ & 048 & 0.819 & 0.566 & 0.442 & $10.0 \pm 1.3$ & 19.6 & 544 & \multirow{3}{*}{0.98} & \multirow{3}{*}{0.51} & \multirow{3}{*}{0.51} & \multirow{3}{*}{ B } \\
\hline $0235+164$ & 080 & 1.128 & 0.666 & 0.452 & $5.7 \pm 0.3$ & 24.7 & 916 & & & & \\
\hline $0235+164$ & 145 & 1.292 & 0.804 & 0.436 & $5.8 \pm 0.3$ & 23.5 & 802 & & & & \\
\hline $0300+470$ & 048 & 0.477 & 0.582 & 0.004 & $29.6 \pm 5.2^{F}$ & 21.5 & 232 & \multirow{3}{*}{0.96} & \multirow{3}{*}{0.18} & \multirow{3}{*}{0.19} & \multirow{3}{*}{ B } \\
\hline $0300+470$ & 080 & 0.454 & 0.515 & 0.003 & $43.9 \pm 8.5^{F}$ & 23.4 & 587 & & & & \\
\hline $0300+470$ & 145 & 0.513 & 0.568 & 0.008 & $52.1 \pm 16.7^{F}$ & 20.9 & 418 & & & & \\
\hline $0306+102$ & 048 & 0.183 & 0.198 & 0.140 & $11.8 \pm 2.4$ & 18.3 & 75 & \multirow{4}{*}{0.83} & \multirow{4}{*}{0.25} & \multirow{4}{*}{0.27} & \\
\hline \multirow[t]{2}{*}{$0306+102$} & 080 & 0.249 & 0.217 & 0.132 & $52.1 \pm 26.4^{F}$ & 21.0 & 430 & & & & Q \\
\hline & & 0.249 & 0.225 & 0.096 & $13.5 \pm 1.7$ & 21.0 & 430 & & & & \\
\hline $0306+102$ & 145 & 0.250 & 0.236 & 0.134 & $12.3 \pm 1.8$ & 19.6 & 247 & & & & \\
\hline $0315+416$ & 048 & 0.107 & 0.067 & 1.000 & $0.2 \pm 0.0^{F}$ & 13.9 & 49 & & & & \\
\hline $0315+416$ & 080 & 0.171 & 0.124 & 1.000 & $0.2 \pm 0.0^{F}$ & 14.0 & 53 & 0.90 & 0.16 & 0.22 & G \\
\hline $0315+416$ & 145 & 0.096 & 0.058 & 1.000 & $0.3 \pm 0.0^{F}$ & 12.4 & 67 & & & & \\
\hline $0316+413$ & 048 & 13.303 & 18.724 & 0.000 & $29.6 \pm 0.6^{F}$ & 21.5 & 563 & & & & \\
\hline $0316+413$ & 080 & 13.954 & 19.217 & 0.000 & $38.2 \pm 0.9^{F}$ & 32.2 & 1490 & 0.97 & 0.30 & 0.30 & Q \\
\hline & & 13.954 & 6.963 & 0.423 & $9.7 \pm 0.7$ & 32.2 & 1490 & & & & \\
\hline $0316+413$ & 145 & 11.392 & 15.462 & 0.000 & $38.0 \pm 2.0^{F}$ & 25.2 & 761 & & & & \\
\hline $0323+022$ & 048 & 0.077 & 0.054 & 1.000 & $0.1 \pm 0.0^{F}$ & 13.2 & 43 & & & & \\
\hline $0323+022$ & 080 & 0.071 & 0.046 & 1.000 & $0.1 \pm 0.0^{F}$ & 13.3 & 72 & 0.83 & 0.48 & 0.72 & B \\
\hline $0323+022$ & 145 & 0.044 & 0.037 & 1.000 & $0.1 \pm 0.0^{F}$ & 11.6 & 32 & & & & \\
\hline $0333+321$ & 048 & 0.308 & 0.397 & 0.001 & $927.6 \pm 4504.4^{F}$ & 18.6 & 239 & & & & \\
\hline $0333+321$ & 080 & 0.370 & 0.407 & 0.007 & $52.1 \pm 16.1^{F}$ & 20.8 & 470 & 0.96 & 0.20 & 0.21 & Q \\
\hline & & 0.370 & 0.421 & 0.004 & $13.5 \pm 1.0$ & 20.8 & 470 & & & & \\
\hline $0333+321$ & 145 & 0.326 & 0.386 & 0.003 & $13.5 \pm 1.1^{P}$ & 19.3 & 351 & & & & \\
\hline
\end{tabular}


Table 1. continued.

\begin{tabular}{|c|c|c|c|c|c|c|c|c|c|c|c|}
\hline Designation & Freq & $\delta_{N}$ & $\bar{A}$ & Fap & Tms & ObT & $N$ & $\overline{\mathrm{VI}}$ & $\overline{\text { NVA }}$ & RMSD & ID \\
\hline $0336-019$ & 048 & 0.296 & 0.286 & 0.234 & $10.0 \pm 1.6$ & 18.8 & 137 & & & & \\
\hline 0336-019 & 080 & 0.400 & 0.406 & 0.021 & $10.4 \pm 0.7$ & 24.5 & 491 & 0.94 & 0.15 & 0.16 & Q \\
\hline 0336-019 & 145 & 0.434 & 0.403 & 0.081 & $11.3 \pm 1.0$ & 24.6 & 397 & & & & \\
\hline $0355+508$ & 048 & 2.655 & 3.698 & 0.000 & $925.7 \pm 2033.4^{F}$ & 18.5 & 180 & & & & \\
\hline $0355+508$ & 080 & 2.981 & 4.076 & 0.000 & $33.5 \pm 1.3^{F}$ & 29.0 & 666 & $*$ & $*$ & * & \\
\hline $0355+508$ & 145 & 3.327 & 4.581 & 0.000 & $37.9 \pm 2.2^{F}$ & 23.6 & 465 & & & & \\
\hline $0404+768$ & 048 & 0.097 & 0.084 & 0.999 & $0.1 \pm 0.0^{F}$ & 8.8 & 34 & & & & \\
\hline $0404+768$ & 080 & 0.181 & 0.187 & 0.945 & $0.1 \pm 0.0^{F}$ & 9.2 & 14 & 0.98 & 0.07 & 0.29 & G \\
\hline $0404+768$ & 145 & 0.223 & 0.178 & 1.000 & $4.9 \pm 2.2^{F}$ & 9.1 & 34 & & & & \\
\hline $0420-014$ & 048 & 0.768 & 0.868 & 0.005 & $19.2 \pm 2.2^{F}$ & 19.0 & 476 & & & & \\
\hline $0420-014$ & 080 & 1.015 & 0.983 & 0.014 & $20.7 \pm 2.3^{P}$ & 21.9 & 911 & 0.98 & 0.23 & 0.23 & Q \\
\hline $0420-014$ & 145 & 0.982 & 0.801 & 0.118 & $22.4 \pm 4.2^{F}$ & 21.7 & 677 & & & & \\
\hline \multirow[t]{2}{*}{$0422+004$} & 048 & 0.336 & 0.426 & 0.004 & $37.6 \pm 10.3^{F}$ & 18.6 & 146 & & & & \\
\hline & & 0.336 & 0.303 & 0.412 & $6.6 \pm 0.8$ & 18.6 & 146 & & & & \\
\hline $0422+004$ & 080 & 0.359 & 0.391 & 0.009 & $1022.1 \pm 6551.7^{F}$ & 20.4 & 468 & 0.94 & 0.36 & 0.37 & B \\
\hline $0422+004$ & 145 & 0.408 & 0.442 & 0.015 & $43.4 \pm 16.2^{F}$ & 17.5 & 343 & & & & \\
\hline \multirow[t]{2}{*}{$0430+052$} & 048 & 0.706 & 0.619 & 0.109 & $10.4 \pm 1.1$ & 19.1 & 470 & & & & \\
\hline & & 0.706 & 0.655 & 0.062 & $4.3 \pm 0.2$ & 19.1 & 470 & & & & \\
\hline \multirow[t]{2}{*}{$0430+052$} & 080 & 2.401 & 2.713 & 0.001 & $86.0 \pm 19.0^{F}$ & 29.2 & 1111 & 0.97 & 0.53 & 0.53 & Q \\
\hline & & 2.401 & 1.567 & 0.234 & $13.6 \pm 1.2$ & 29.2 & 1111 & & & & \\
\hline \multirow[t]{2}{*}{$0430+052$} & 145 & 1.459 & 1.392 & 0.019 & $1239.3 \pm 7850.1^{F}$ & 24.8 & 827 & & & & \\
\hline & & 1.459 & 1.040 & 0.221 & $11.8 \pm 1.1$ & 24.8 & 827 & & & & \\
\hline $0440-003$ & 048 & 0.293 & 0.385 & 0.042 & $8.5 \pm 1.6$ & 16.1 & 14 & & & & \\
\hline \multirow[t]{6}{*}{ 0440-003 } & 080 & 0.292 & 0.370 & 0.014 & $17.9 \pm 4.3^{F}$ & 16.1 & 57 & 0.90 & 0.23 & 0.27 & Q \\
\hline & & 0.292 & 0.362 & 0.022 & $8.7 \pm 1.1$ & 16.1 & 57 & & & & \\
\hline & & 0.292 & 0.330 & 0.105 & $5.4 \pm 0.6$ & 16.1 & 57 & & & & \\
\hline & & 0.292 & 0.309 & 0.262 & $3.1 \pm 0.2$ & 16.1 & 57 & & & & \\
\hline & & 0.292 & 0.300 & 0.368 & $2.6 \pm 0.2$ & 16.1 & 57 & & & & \\
\hline & & 0.292 & 0.298 & 0.386 & $2.2 \pm 0.1$ & 16.1 & 57 & & & & \\
\hline 0440-003 & 145 & 0.321 & 0.408 & 0.034 & $8.5 \pm 1.4$ & 16.3 & 28 & & & & \\
\hline $0454-234$ & 048 & 0.196 & 0.248 & 0.400 & $2.2 \pm 0.3$ & 8.6 & 9 & & & & \\
\hline $0454-234$ & 080 & 0.304 & 0.361 & 0.128 & $749.2 \pm 16092.2^{F}$ & 15.0 & 25 & 0.95 & 0.17 & 0.27 & Q \\
\hline $0454-234$ & 145 & 0.386 & 0.466 & 0.300 & $107.1 \pm 3025.0^{F}$ & 2.1 & 13 & & & & \\
\hline \multirow[t]{3}{*}{$0458-020$} & 048 & 0.579 & 0.584 & 0.333 & $10.7 \pm 4.1^{P}$ & 10.8 & 75 & & & & \\
\hline & & 0.579 & 0.580 & 0.354 & $4.1 \pm 0.6$ & 10.8 & 75 & & & & \\
\hline & & 0.579 & 0.562 & 0.477 & $2.8 \pm 0.3$ & 10.8 & 75 & & & & \\
\hline 0458-020 & 080 & 0.790 & 0.903 & 0.014 & $20.5 \pm 4.4^{F}$ & 16.1 & 212 & 0.94 & 0.25 & 0.26 & Q \\
\hline $0458-020$ & 145 & 0.683 & 0.784 & 0.019 & $405.0 \pm 3817.0^{F}$ & 8.1 & 161 & & & & \\
\hline
\end{tabular}


Table 1. continued.

\begin{tabular}{|c|c|c|c|c|c|c|c|c|c|c|c|}
\hline$\overline{\text { Designation }}$ & Freq & $\delta_{N}$ & $\bar{A}$ & Fap & Tms & $\overline{\mathrm{ObT}}$ & $\bar{N}$ & $\overline{\overline{\mathrm{VI}}}$ & $\overline{\mathrm{NVA}}$ & RMSD & $\overline{\mathrm{ID}}$ \\
\hline $0518+165$ & 048 & 0.137 & 0.140 & 0.036 & $874.8 \pm 7815.4^{F}$ & 17.5 & 312 & & & & \\
\hline $0518+165$ & 080 & 0.191 & 0.181 & 0.070 & $24.4 \pm 4.7^{F}$ & 23.9 & 388 & 0.94 & 0.25 & 0.26 & $\mathrm{Q}$ \\
\hline $0518+165$ & 145 & 0.132 & 0.099 & 0.347 & $835.1 \pm 10224.4^{F}$ & 16.7 & 477 & & & & \\
\hline $0521-365$ & 048 & 0.392 & 0.346 & 0.559 & $920.7 \pm 16979.0^{F}$ & 18.4 & 127 & & & & \\
\hline $0521-365$ & 080 & 0.510 & 0.529 & 0.033 & $897.4 \pm 7929.8^{F}$ & 17.9 & 306 & 0.96 & 0.08 & 0.10 & Q \\
\hline 0521-365 & 145 & 0.731 & 0.674 & 0.194 & $64.0 \pm 53.9^{F}$ & 19.5 & 228 & & & & \\
\hline \multirow[t]{4}{*}{$0528+134$} & 048 & 1.005 & 1.054 & 0.065 & $14.2 \pm 2.5^{P}$ & 18.4 & 173 & & & & \\
\hline & & 1.005 & 1.139 & 0.021 & $7.2 \pm 0.5$ & 18.4 & 173 & & & & \\
\hline & & 1.005 & 1.118 & 0.028 & $4.8 \pm 0.2$ & 18.4 & 173 & & & & \\
\hline & & 1.005 & 0.892 & 0.378 & $3.7 \pm 0.2$ & 18.4 & 173 & & & & \\
\hline \multirow[t]{3}{*}{$0528+134$} & 080 & 1.749 & 1.504 & 0.131 & $12.9 \pm 1.5$ & 23.0 & 468 & 0.97 & 0.40 & 0.40 & $\mathrm{Q}$ \\
\hline & & 1.749 & 1.256 & 0.439 & $7.4 \pm 0.6$ & 23.0 & 468 & & & & \\
\hline & & 1.749 & 1.529 & 0.113 & $4.9 \pm 0.2$ & 23.0 & 468 & & & & \\
\hline \multirow[t]{4}{*}{$0528+134$} & 145 & 2.272 & 2.323 & 0.037 & $16.8 \pm 2.7^{P}$ & 18.6 & 311 & & & & \\
\hline & & 2.272 & 2.577 & 0.008 & $8.5 \pm 0.5$ & 18.6 & 311 & & & & \\
\hline & & 2.272 & 2.105 & 0.116 & $5.6 \pm 0.4$ & 18.6 & 311 & & & & \\
\hline & & 2.272 & 2.258 & 0.053 & $4.1 \pm 0.2$ & 18.6 & 311 & & & & \\
\hline $0528-250$ & 048 & 0.115 & 0.070 & 1.000 & $1.4 \pm 0.1^{F}$ & 19.2 & 73 & & & & \\
\hline $0528-250$ & 080 & 0.104 & 0.086 & 0.988 & $6.9 \pm 2.7^{F}$ & 10.5 & 60 & 0.81 & 0.10 & 0.19 & Q \\
\hline $0528-250$ & 145 & 0.121 & 0.067 & 1.000 & $0.2 \pm 0.0^{F}$ & 17.0 & 80 & & & & \\
\hline $0538+498$ & 048 & 0.173 & 0.154 & 0.568 & $22.1 \pm 12.5^{F}$ & 14.8 & 118 & & & & \\
\hline $0538+498$ & 080 & 0.222 & 0.187 & 0.665 & $44.2 \pm 26.4^{F}$ & 28.0 & 141 & 0.97 & 0.04 & 0.10 & $\mathrm{Q}$ \\
\hline $0538+498$ & 145 & 0.221 & 0.185 & 0.817 & $13.5 \pm 5.1^{F}$ & 15.4 & 108 & & & & \\
\hline $0552+398$ & 048 & 0.285 & 0.263 & 0.687 & $8.0 \pm 2.4^{F}$ & 11.9 & 75 & & & & \\
\hline $0552+398$ & 080 & 1.127 & 1.426 & 0.001 & $26.9 \pm 2.5^{P}$ & 28.5 & 274 & 0.95 & 0.19 & 0.20 & Q \\
\hline \multirow[t]{2}{*}{$0552+398$} & 145 & 1.058 & 1.220 & 0.008 & $20.6 \pm 3.2^{F}$ & 19.1 & 271 & & & & \\
\hline & & 1.058 & 1.208 & 0.010 & $14.2 \pm 1.6^{P}$ & 19.1 & 271 & & & & \\
\hline $0605+480$ & 048 & 0.077 & 0.046 & 1.000 & $2.8 \pm 0.5^{F}$ & 14.5 & 55 & & & & \\
\hline $0605+480$ & 080 & 0.174 & 0.111 & 1.000 & $0.1 \pm 0.0^{F}$ & 15.9 & 52 & 0.75 & 0.19 & 0.25 & G \\
\hline $0605+480$ & 145 & 0.056 & 0.033 & 1.000 & $0.1 \pm 0.0^{F}$ & 14.3 & 51 & & & & \\
\hline $0605-085$ & 048 & 0.349 & 0.391 & 0.009 & $7.3 \pm 0.5$ & 16.1 & 347 & & & & \\
\hline $0605-085$ & 080 & 0.460 & 0.582 & 0.001 & $7.2 \pm 0.2$ & 24.5 & 510 & 0.91 & 0.17 & 0.18 & Q \\
\hline \multirow[t]{2}{*}{ 0605-085 } & 145 & 0.562 & 0.393 & 0.472 & $831.4 \pm 10977.6^{F}$ & 16.6 & 490 & & & & \\
\hline & & 0.562 & 0.705 & 0.001 & $7.3 \pm 0.3$ & 16.6 & 490 & & & & \\
\hline $0607-157$ & 048 & 1.233 & 1.312 & 0.011 & $1060.0 \pm 7037.1^{F}$ & 21.2 & 483 & & & & \\
\hline \multirow[t]{2}{*}{$0607-157$} & 080 & 2.014 & 2.275 & 0.002 & $123.1 \pm 54.6^{F}$ & 24.3 & 820 & 0.97 & 0.57 & 0.57 & Q \\
\hline & & 2.014 & 1.904 & 0.022 & $10.9 \pm 0.6$ & 24.3 & 820 & & & & \\
\hline \multirow[t]{3}{*}{ 0607-157 } & 145 & 2.349 & 2.625 & 0.003 & $1001.6 \pm 4829.6^{F}$ & 20.0 & 719 & & & & \\
\hline & & 2.349 & 2.302 & 0.018 & $10.4 \pm 0.7$ & 20.0 & 719 & & & & \\
\hline & & 2.349 & 1.524 & 0.421 & $6.5 \pm 0.5$ & 20.0 & 719 & & & & \\
\hline
\end{tabular}


Table 1. continued.

\begin{tabular}{|c|c|c|c|c|c|c|c|c|c|c|c|}
\hline Designation & Freq & $\delta_{N}$ & $\mathrm{~A}$ & Fap & Tms & ObT & $N$ & VI & NVA & RMSD & ID \\
\hline $\begin{array}{l}0710+439 \\
0710+439 \\
0710+439 \\
\end{array}$ & $\begin{array}{l}048 \\
080 \\
145 \\
\end{array}$ & $\begin{array}{l}0.085 \\
0.133 \\
0.055 \\
\end{array}$ & $\begin{array}{l}0.053 \\
0.088 \\
0.036 \\
\end{array}$ & $\begin{array}{l}1.000 \\
1.000 \\
1.000 \\
\end{array}$ & $\begin{array}{l}0.1 \pm 0.0^{F} \\
0.3 \pm 0.0^{F} \\
0.2 \pm 0.0^{F}\end{array}$ & $\begin{array}{l}13.9 \\
21.9 \\
14.5 \\
\end{array}$ & $\begin{array}{l}51 \\
58 \\
62 \\
\end{array}$ & 0.95 & 0.10 & 0.17 & Q \\
\hline $\begin{array}{l}0711+356 \\
0711+356 \\
0711+356 \\
\end{array}$ & $\begin{array}{l}048 \\
080 \\
145 \\
\end{array}$ & $\begin{array}{l}0.127 \\
0.134 \\
0.060 \\
\end{array}$ & $\begin{array}{l}0.142 \\
0.087 \\
0.035 \\
\end{array}$ & $\begin{array}{l}0.051 \\
1.000 \\
1.000 \\
\end{array}$ & $\begin{array}{r}711.0 \pm 8723.3^{F} \\
805.2 \pm 24638.6^{F} \\
0.1 \pm 0.0^{F} \\
\end{array}$ & $\begin{array}{l}14.2 \\
16.1 \\
14.5\end{array}$ & $\begin{array}{l}112 \\
111 \\
107 \\
\end{array}$ & 0.80 & 0.17 & 0.22 & Q \\
\hline $\begin{array}{l}0716+714 \\
0716+714\end{array}$ & $\begin{array}{l}080 \\
145\end{array}$ & $\begin{array}{l}0.215 \\
0.215 \\
0.215 \\
0.215 \\
0.300 \\
0.375 \\
0.375 \\
0.375 \\
\end{array}$ & $\begin{array}{l}0.191 \\
0.192 \\
0.187 \\
0.199 \\
0.188 \\
0.337 \\
0.324 \\
0.330 \\
\end{array}$ & $\begin{array}{l}0.283 \\
0.275 \\
0.345 \\
0.200 \\
0.987 \\
0.097 \\
0.140 \\
0.117\end{array}$ & $\begin{array}{r}15.0 \pm 3.6^{P} \\
9.3 \pm 1.4 \\
7.8 \pm 1.0 \\
5.7 \pm 0.5 \\
4.1 \pm 0.4^{F} \\
16.8 \pm 3.0^{P} \\
9.7 \pm 1.1 \\
5.4 \pm 0.3 \\
\end{array}$ & $\begin{array}{l}17.6 \\
17.6 \\
17.6 \\
17.6 \\
17.8 \\
18.1 \\
18.1 \\
18.1 \\
\end{array}$ & $\begin{array}{l}219 \\
219 \\
219 \\
219 \\
214 \\
439 \\
439 \\
439 \\
\end{array}$ & 0.95 & 0.31 & 0.34 & B \\
\hline $\begin{array}{l}0723+679 \\
0723+679 \\
0723+679 \\
\end{array}$ & $\begin{array}{l}048 \\
080 \\
145 \\
\end{array}$ & $\begin{array}{l}0.090 \\
0.194 \\
0.111 \\
\end{array}$ & $\begin{array}{l}0.047 \\
0.121 \\
0.068 \\
\end{array}$ & $\begin{array}{l}1.000 \\
1.000 \\
1.000 \\
\end{array}$ & $\begin{array}{l}0.7 \pm 0.0^{F} \\
0.1 \pm 0.0^{F} \\
2.6 \pm 0.3^{F} \\
\end{array}$ & $\begin{array}{l}13.9 \\
17.5 \\
17.4 \\
\end{array}$ & $\begin{array}{r}115 \\
90 \\
115\end{array}$ & 0.82 & 0.24 & 0.29 & Q \\
\hline $\begin{array}{l}0735+178 \\
0735+178 \\
0735+178 \\
\end{array}$ & $\begin{array}{l}048 \\
080 \\
145 \\
\end{array}$ & $\begin{array}{l}0.834 \\
0.923 \\
1.039 \\
\end{array}$ & $\begin{array}{l}1.008 \\
0.944 \\
1.179 \\
\end{array}$ & $\begin{array}{l}0.002 \\
0.011 \\
0.003 \\
\end{array}$ & $\begin{array}{r}12.9 \pm 0.9^{P} \\
15.0 \pm 1.2^{P} \\
13.5 \pm 0.9 \\
\end{array}$ & $\begin{array}{l}19.2 \\
22.1 \\
21.6 \\
\end{array}$ & $\begin{array}{l}362 \\
679 \\
607 \\
\end{array}$ & 0.97 & 0.38 & 0.39 & B \\
\hline $\begin{array}{l}0754+100 \\
0754+100\end{array}$ & $\begin{array}{l}080 \\
145\end{array}$ & $\begin{array}{l}0.523 \\
0.523 \\
0.523 \\
0.617 \\
0.605 \\
0.605 \\
\end{array}$ & $\begin{array}{l}0.542 \\
0.538 \\
0.529 \\
0.691 \\
0.674 \\
0.524 \\
\end{array}$ & $\begin{array}{l}0.167 \\
0.182 \\
0.222 \\
0.014 \\
0.015 \\
0.278 \\
\end{array}$ & $\begin{array}{r}15.0 \pm 3.6^{P} \\
11.8 \pm 2.3 \\
6.6 \pm 0.7 \\
10.4 \pm 0.8 \\
11.3 \pm 1.0 \\
6.8 \pm 0.6 \\
\end{array}$ & $\begin{array}{l}19.2 \\
19.2 \\
19.2 \\
21.1 \\
20.3 \\
20.3\end{array}$ & $\begin{array}{l}100 \\
100 \\
100 \\
261 \\
263 \\
263 \\
\end{array}$ & 0.95 & 0.36 & 0.37 & B \\
\hline $\begin{array}{l}0804+499 \\
0804+499 \\
0804+499 \\
\end{array}$ & $\begin{array}{l}048 \\
080 \\
145 \\
\end{array}$ & $\begin{array}{l}0.297 \\
0.469 \\
0.502 \\
\end{array}$ & $\begin{array}{l}0.251 \\
0.322 \\
0.366 \\
\end{array}$ & $\begin{array}{l}0.567 \\
0.977 \\
0.930 \\
\end{array}$ & $\begin{array}{l}5.8 \pm 0.8^{F} \\
1.0 \pm 0.0^{F} \\
1.3 \pm 0.0^{F}\end{array}$ & $\begin{array}{l}15.3 \\
18.8 \\
18.7\end{array}$ & $\begin{array}{l}164 \\
170 \\
166 \\
\end{array}$ & 0.87 & 0.38 & 0.39 & Q \\
\hline $\begin{array}{l}0808+019 \\
0808+019 \\
0808+019 \\
\end{array}$ & $\begin{array}{l}048 \\
080 \\
145 \\
\end{array}$ & $\begin{array}{l}0.269 \\
0.329 \\
0.312 \\
\end{array}$ & $\begin{array}{l}0.211 \\
0.235 \\
0.212 \\
\end{array}$ & $\begin{array}{l}0.990 \\
0.998 \\
1.000 \\
\end{array}$ & $\begin{array}{l}2.7 \pm 0.2^{F} \\
2.8 \pm 0.2^{F} \\
4.5 \pm 0.6^{F}\end{array}$ & $\begin{array}{l}19.2 \\
19.4 \\
19.5 \\
\end{array}$ & $\begin{array}{r}80 \\
101 \\
99 \\
\end{array}$ & 0.94 & 0.30 & 0.32 & B \\
\hline $\begin{array}{l}0809+483 \\
0809+483 \\
0809+483 \\
\end{array}$ & $\begin{array}{l}048 \\
080 \\
145 \\
\end{array}$ & $\begin{array}{l}0.081 \\
0.134 \\
0.085 \\
\end{array}$ & $\begin{array}{l}0.064 \\
0.073 \\
0.049 \\
\end{array}$ & $\begin{array}{l}1.000 \\
1.000 \\
1.000 \\
\end{array}$ & $\begin{array}{l}0.1 \pm 0.0^{F} \\
0.1 \pm 0.0^{F} \\
0.1 \pm 0.0^{F} \\
\end{array}$ & $\begin{array}{l}12.4 \\
31.4 \\
14.5 \\
\end{array}$ & $\begin{array}{l}38 \\
68 \\
81 \\
\end{array}$ & 0.96 & 0.04 & 0.13 & $\mathrm{Q}$ \\
\hline $\begin{array}{l}0814+425 \\
0814+425 \\
0814+425\end{array}$ & $\begin{array}{l}048 \\
080 \\
145\end{array}$ & $\begin{array}{l}0.436 \\
0.337 \\
0.454\end{array}$ & $\begin{array}{l}0.570 \\
0.377 \\
0.548\end{array}$ & $\begin{array}{l}0.002 \\
0.007 \\
0.004\end{array}$ & $\begin{array}{l}20.6 \pm 2.5^{F} \\
20.7 \pm 2.5^{P} \\
19.2 \pm 2.1^{P}\end{array}$ & $\begin{array}{l}19.1 \\
21.9 \\
21.7\end{array}$ & $\begin{array}{l}150 \\
407 \\
263\end{array}$ & 0.94 & 0.18 & 0.19 & B \\
\hline
\end{tabular}


Table 1. continued.

\begin{tabular}{|c|c|c|c|c|c|c|c|c|c|c|c|}
\hline Designation & Freq & $\delta_{N}$ & $\mathrm{~A}$ & $\overline{\text { Fap }}$ & Tms & $\overline{\mathrm{ObT}}$ & $\bar{N}$ & $\overline{\mathrm{VI}}$ & $\overline{\text { NVA }}$ & RMSD & ID \\
\hline $\begin{array}{l}0818-128 \\
0818-128 \\
0818-128\end{array}$ & $\begin{array}{l}048 \\
080 \\
145\end{array}$ & $\begin{array}{l}0.238 \\
0.243 \\
0.268 \\
\end{array}$ & $\begin{array}{l}0.245 \\
0.226 \\
0.250\end{array}$ & $\begin{array}{l}0.287 \\
0.512 \\
0.491 \\
\end{array}$ & $\begin{array}{r}915.4 \pm 17161.3^{F} \\
64.0 \pm 81.0^{F} \\
8.8 \pm 1.6\end{array}$ & $\begin{array}{l}18.3 \\
19.6 \\
18.1\end{array}$ & $\begin{array}{l}70 \\
97 \\
99\end{array}$ & 0.96 & 0.26 & 0.28 & B \\
\hline $\begin{array}{l}0829+046 \\
0829+046 \\
0829+046\end{array}$ & $\begin{array}{l}048 \\
080 \\
145\end{array}$ & $\begin{array}{l}0.295 \\
0.445 \\
0.498\end{array}$ & $\begin{array}{l}0.279 \\
0.486 \\
0.476\end{array}$ & $\begin{array}{l}0.495 \\
0.033 \\
0.231\end{array}$ & $\begin{array}{l}15.0 \pm 4.7^{P} \\
15.9 \pm 2.4^{P} \\
16.8 \pm 4.2^{P}\end{array}$ & $\begin{array}{l}18.6 \\
21.0 \\
19.6\end{array}$ & $\begin{array}{r}90 \\
187 \\
153\end{array}$ & 0.94 & 0.31 & 0.32 & B \\
\hline $\begin{array}{l}0831+557 \\
0831+557 \\
0831+557 \\
\end{array}$ & $\begin{array}{l}048 \\
080 \\
145 \\
\end{array}$ & $\begin{array}{l}0.159 \\
0.193 \\
0.162 \\
\end{array}$ & $\begin{array}{l}0.115 \\
0.132 \\
0.108 \\
\end{array}$ & $\begin{array}{l}1.000 \\
1.000 \\
1.000 \\
\end{array}$ & $\begin{array}{l}0.4 \pm 0.0^{F} \\
0.1 \pm 0.0^{F} \\
0.2 \pm 0.0^{F} \\
\end{array}$ & $\begin{array}{l}13.6 \\
24.8 \\
14.3 \\
\end{array}$ & $\begin{array}{l}45 \\
61 \\
50 \\
\end{array}$ & 0.95 & 0.05 & 0.14 & G \\
\hline $\begin{array}{l}0836+710 \\
0836+710 \\
0836+710\end{array}$ & $\begin{array}{l}048 \\
080\end{array}$ & $\begin{array}{l}0.207 \\
0.429 \\
0.429 \\
0.428 \\
0.428 \\
0.428\end{array}$ & $\begin{array}{l}0.145 \\
0.451 \\
0.399 \\
0.384 \\
0.444 \\
0.380\end{array}$ & $\begin{array}{l}0.964 \\
0.121 \\
0.444 \\
0.257 \\
0.053 \\
0.282\end{array}$ & $\begin{array}{r}839.4 \pm 18773.4^{F} \\
838.0 \pm 11917.1^{F} \\
8.2 \pm 1.5 \\
840.5 \pm 11460.5^{F} \\
9.0 \pm 1.0 \\
5.7 \pm 0.5\end{array}$ & $\begin{array}{l}16.8 \\
16.8 \\
16.8 \\
16.8 \\
16.8 \\
16.8\end{array}$ & $\begin{array}{l}171 \\
111 \\
111 \\
221 \\
221 \\
221\end{array}$ & 0.97 & 0.20 & 0.23 & Q \\
\hline $\begin{array}{l}0838+133 \\
0838+133 \\
0838+133 \\
\end{array}$ & $\begin{array}{l}048 \\
080 \\
145\end{array}$ & $\begin{array}{l}0.092 \\
0.147 \\
0.180 \\
\end{array}$ & $\begin{array}{l}0.072 \\
0.106 \\
0.120 \\
\end{array}$ & $\begin{array}{l}0.985 \\
0.990 \\
1.000 \\
\end{array}$ & $\begin{array}{l}7.7 \pm 2.3^{F} \\
7.8 \pm 1.5^{F} \\
1.8 \pm 0.2^{F}\end{array}$ & $\begin{array}{l}13.9 \\
20.8 \\
12.5 \\
\end{array}$ & $\begin{array}{r}86 \\
121 \\
49 \\
\end{array}$ & 0.89 & 0.10 & 0.15 & Q \\
\hline $\begin{array}{l}0850+581 \\
0850+581 \\
0850+581\end{array}$ & $\begin{array}{l}048 \\
080 \\
145\end{array}$ & $\begin{array}{l}0.066 \\
0.164 \\
0.077\end{array}$ & $\begin{array}{l}0.073 \\
0.107 \\
0.052 \\
\end{array}$ & $\begin{array}{l}0.152 \\
1.000 \\
1.000\end{array}$ & $\begin{array}{r}114.4 \pm 338.7^{F} \\
0.1 \pm 0.0^{F} \\
725.3 \pm 25955.0^{F}\end{array}$ & $\begin{array}{l}13.9 \\
13.6 \\
14.5\end{array}$ & $\begin{array}{l}54 \\
47 \\
72\end{array}$ & 0.88 & 0.15 & 0.22 & Q \\
\hline $0851+202$ & 080 & $\begin{array}{l}0.904 \\
0.904 \\
1.363 \\
1.363 \\
1.363 \\
1.728\end{array}$ & $\begin{array}{l}1.028 \\
0.608 \\
1.158 \\
1.199 \\
0.901 \\
1.964\end{array}$ & $\begin{array}{l}0.003 \\
0.445 \\
0.049 \\
0.036 \\
0.266 \\
0.002\end{array}$ & $\begin{array}{r}26.7 \pm 3.5^{F} \\
8.8 \pm 1.0 \\
1411.3 \pm 10062.4^{F} \\
18.0 \pm 1.6 \\
9.4 \pm 0.6 \\
22.4 \pm 1.8^{P}\end{array}$ & $\begin{array}{l}20.1 \\
20.1 \\
28.2 \\
28.2 \\
28.2 \\
24.7\end{array}$ & $\begin{array}{l}604 \\
604 \\
966 \\
966 \\
966 \\
815\end{array}$ & 0.97 & 0.37 & 0.37 & B \\
\hline $\begin{array}{l}0859+470 \\
0859+470 \\
0859+470\end{array}$ & $\begin{array}{l}048 \\
080 \\
145\end{array}$ & $\begin{array}{l}0.159 \\
0.150 \\
0.117\end{array}$ & $\begin{array}{l}0.136 \\
0.112 \\
0.094\end{array}$ & $\begin{array}{l}0.971 \\
1.000 \\
0.994\end{array}$ & $\begin{array}{r}14.1 \pm 7.8^{F} \\
11.3 \pm 5.0^{F} \\
736.8 \pm 22479.3^{F}\end{array}$ & $\begin{array}{l}15.0 \\
16.3 \\
14.7\end{array}$ & $\begin{array}{l}56 \\
70 \\
61\end{array}$ & 0.81 & 0.12 & 0.18 & Q \\
\hline $\begin{array}{l}0906+430 \\
0906+430\end{array}$ & $\begin{array}{l}048 \\
080\end{array}$ & $\begin{array}{l}0.107 \\
0.222 \\
0.222 \\
0.216\end{array}$ & $\begin{array}{l}0.097 \\
0.245 \\
0.199 \\
0.267\end{array}$ & $\begin{array}{l}0.359 \\
0.025 \\
0.289 \\
0.005\end{array}$ & $\begin{array}{r}933.4 \pm 14570.3^{F} \\
983.7 \pm 9249.3^{F} \\
14.2 \pm 2.9^{P} \\
947.4 \pm 6651.9^{F}\end{array}$ & $\begin{array}{l}18.7 \\
19.7 \\
19.7 \\
18.9\end{array}$ & $\begin{array}{l}166 \\
200 \\
200 \\
174\end{array}$ & 0.92 & 0.15 & 0.17 & Q \\
\hline $\begin{array}{l}0912+297 \\
0912+297 \\
0912+297\end{array}$ & $\begin{array}{l}048 \\
080 \\
145\end{array}$ & $\begin{array}{l}0.059 \\
0.103 \\
0.053\end{array}$ & $\begin{array}{l}0.047 \\
0.052 \\
0.037\end{array}$ & $\begin{array}{l}0.997 \\
1.000 \\
1.000\end{array}$ & $\begin{array}{r}0.1 \pm 0.0^{F} \\
1.3 \pm 0.1^{F} \\
902.7 \pm 29308.9^{F}\end{array}$ & $\begin{array}{l}18.4 \\
18.9 \\
18.1\end{array}$ & $\begin{array}{l}63 \\
83 \\
79\end{array}$ & 0.81 & 0.34 & 0.44 & B \\
\hline
\end{tabular}


J. H. Fan et al.: Radio variability properties for radio sources, Online Material $p 9$

Table 1. continued.

\begin{tabular}{|c|c|c|c|c|c|c|c|c|c|c|c|}
\hline Designation & Freq & $\delta_{N}$ & $\mathrm{~A}$ & Fap & Tms & ObT & $N$ & $\mathrm{VI}$ & NVA & RMSD & ID \\
\hline $0917+458$ & 048 & 0.131 & 0.091 & 1.000 & $0.3 \pm 0.0^{F}$ & 14.2 & 54 & \multirow{3}{*}{0.90} & \multirow{3}{*}{0.08} & \multirow{3}{*}{0.16} & \multirow{3}{*}{ Q } \\
\hline $0917+458$ & 080 & 0.130 & 0.095 & 1.000 & $0.1 \pm 0.0^{F}$ & 15.9 & 60 & & & & \\
\hline $0917+458$ & 145 & 0.088 & 0.091 & 0.333 & $714.7 \pm 14496.6^{F}$ & 14.3 & 59 & & & & \\
\hline $0923+392$ & 048 & 1.870 & 2.616 & 0.000 & $24.3 \pm 0.6^{F}$ & 21.0 & 476 & \multirow{3}{*}{0.95} & \multirow{3}{*}{0.32} & \multirow{3}{*}{0.32} & \multirow{3}{*}{ Q } \\
\hline $0923+392$ & 080 & 2.880 & 3.782 & 0.000 & $22.5 \pm 0.7^{P}$ & 31.9 & 1008 & & & & \\
\hline $0923+392$ & 145 & 3.166 & 4.398 & 0.000 & $24.4 \pm 0.6^{P}$ & 25.0 & 656 & & & & \\
\hline $0951+699$ & 048 & 0.096 & 0.059 & 1.000 & $0.1 \pm 0.0^{F}$ & 13.2 & 45 & \multirow{3}{*}{0.88} & \multirow{3}{*}{0.12} & \multirow{3}{*}{0.20} & \multirow{3}{*}{ G } \\
\hline $0951+699$ & 080 & 0.306 & 0.219 & 1.000 & $0.3 \pm 0.0^{F}$ & 15.9 & 38 & & & & \\
\hline $0951+699$ & 145 & 0.132 & 0.085 & 1.000 & $1.0 \pm 0.1^{F}$ & 14.0 & 53 & & & & \\
\hline $0954+556$ & 048 & 0.077 & 0.038 & 1.000 & $0.1 \pm 0.0^{F}$ & 18.7 & 86 & \multirow{3}{*}{0.88} & \multirow{3}{*}{0.06} & \multirow{3}{*}{0.12} & \multirow{3}{*}{ Q } \\
\hline $0954+556$ & 080 & 0.131 & 0.063 & 1.000 & $0.3 \pm 0.0^{F}$ & 24.8 & 111 & & & & \\
\hline $0954+556$ & 145 & 0.099 & 0.048 & 1.000 & $0.2 \pm 0.0^{F}$ & 18.7 & 97 & & & & \\
\hline $0954+658$ & 048 & 0.321 & 0.376 & 0.016 & $19.1 \pm 4.7^{F}$ & 14.6 & 141 & \multirow{3}{*}{0.96} & \multirow{3}{*}{0.46} & \multirow{3}{*}{0.48} & \multirow{3}{*}{ B } \\
\hline $0954+658$ & 080 & 0.431 & 0.467 & 0.070 & $20.5 \pm 7.6^{F}$ & 14.0 & 122 & & & & \\
\hline $0954+658$ & 145 & 0.266 & 0.311 & 0.012 & $588.3 \pm 4944.7^{F}$ & 11.8 & 183 & & & & \\
\hline $0957+227$ & 048 & 0.062 & 0.035 & 1.000 & $0.1 \pm 0.0^{F}$ & 18.4 & 62 & \multirow{3}{*}{0.77} & \multirow{3}{*}{0.20} & \multirow{3}{*}{0.31} & \\
\hline $0957+227$ & 080 & 0.081 & 0.038 & 1.000 & $0.1 \pm 0.0^{F}$ & 19.2 & 78 & & & & B \\
\hline $0957+227$ & 145 & 0.052 & 0.036 & 1.000 & $0.1 \pm 0.0^{F}$ & 19.5 & 79 & & & & \\
\hline $1003+351$ & 048 & 0.090 & 0.053 & 1.000 & $0.2 \pm 0.0^{F}$ & 14.2 & 53 & & & & \\
\hline $1003+351$ & 080 & 0.131 & 0.099 & 1.000 & $22.2 \pm 23.1^{F}$ & 15.8 & 51 & 0.75 & 0.10 & 0.19 & Q \\
\hline $1003+351$ & 145 & 0.067 & 0.048 & 1.000 & $0.1 \pm 0.0^{F}$ & 12.8 & 48 & & & & \\
\hline $1031+567$ & 048 & 0.080 & 0.057 & 1.000 & $0.4 \pm 0.0^{F}$ & 13.7 & 57 & & & & \\
\hline $1031+567$ & 080 & 0.150 & 0.101 & 1.000 & $2.6 \pm 0.3^{F}$ & 18.4 & 53 & 0.76 & 0.16 & 0.23 & G \\
\hline $1031+567$ & 145 & 0.075 & 0.056 & 1.000 & $0.3 \pm 0.0^{F}$ & 14.3 & 51 & & & & \\
\hline $1034-293$ & 048 & 0.328 & 0.218 & 1.000 & $9.4 \pm 3.2^{F}$ & 19.2 & 79 & & & & \\
\hline $1034-293$ & 080 & 0.353 & 0.208 & 1.000 & $9.4 \pm 3.0^{F}$ & 21.1 & 101 & 0.87 & 0.20 & 0.22 & Q \\
\hline $1034-293$ & 145 & 0.483 & 0.359 & 0.999 & $9.0 \pm 2.6^{F}$ & 18.5 & 83 & & & & \\
\hline $1038+528$ & 048 & 0.133 & 0.123 & 0.850 & $14.0 \pm 10.2^{F}$ & 10.5 & 49 & & & & \\
\hline $1038+528$ & 080 & 0.233 & 0.202 & 0.992 & $537.9 \pm 18005.6^{F}$ & 10.8 & 41 & 0.93 & 0.28 & 0.33 & Q \\
\hline $1038+528$ & 145 & 0.251 & 0.314 & 0.022 & $9.3 \pm 2.0^{P}$ & 10.8 & 51 & & & & \\
\hline $1040+123$ & 048 & 0.079 & 0.046 & 1.000 & $12.8 \pm 9.3^{F}$ & 13.9 & 90 & & & & \\
\hline $1040+123$ & 080 & 0.140 & 0.071 & 1.000 & $738.8 \pm 26306.2^{F}$ & 14.8 & 146 & 0.85 & 0.09 & 0.13 & Q \\
\hline $1040+123$ & 145 & 0.068 & 0.058 & 0.732 & $24.0 \pm 18.2^{F}$ & 13.0 & 114 & & & & \\
\hline $1055+018$ & 048 & 0.250 & 0.208 & 0.515 & $2.6 \pm 0.1^{F}$ & 16.5 & 200 & & & & \\
\hline $1055+018$ & 080 & 0.476 & 0.454 & 0.041 & $26.9 \pm 3.6^{P}$ & 32.2 & 513 & 0.97 & 0.13 & 0.14 & Q \\
\hline $1055+018$ & 145 & 0.718 & 0.670 & 0.073 & $22.4 \pm 4.3^{F}$ & 21.7 & 413 & & & & \\
\hline & & 0.718 & 0.560 & 0.329 & $5.0 \pm 0.3$ & 21.7 & 413 & & & & \\
\hline & 048 & 0.082 & 0.045 & 1.000 & $0.1 \pm 0.0^{F}$ & 14.2 & 69 & & & & \\
\hline $1100+772$ & 080 & 0.210 & 0.176 & 0.997 & $10.8 \pm 4.9^{F}$ & 15.9 & 46 & 0.80 & 0.33 & 0.41 & B \\
\hline $1100+772$ & 145 & 0.075 & 0.059 & 1.000 & $0.1 \pm 0.0^{F}$ & 3.0 & 14 & & & & \\
\hline
\end{tabular}


J. H. Fan et al.: Radio variability properties for radio sources, Online Material p 10

Table 1. continued.

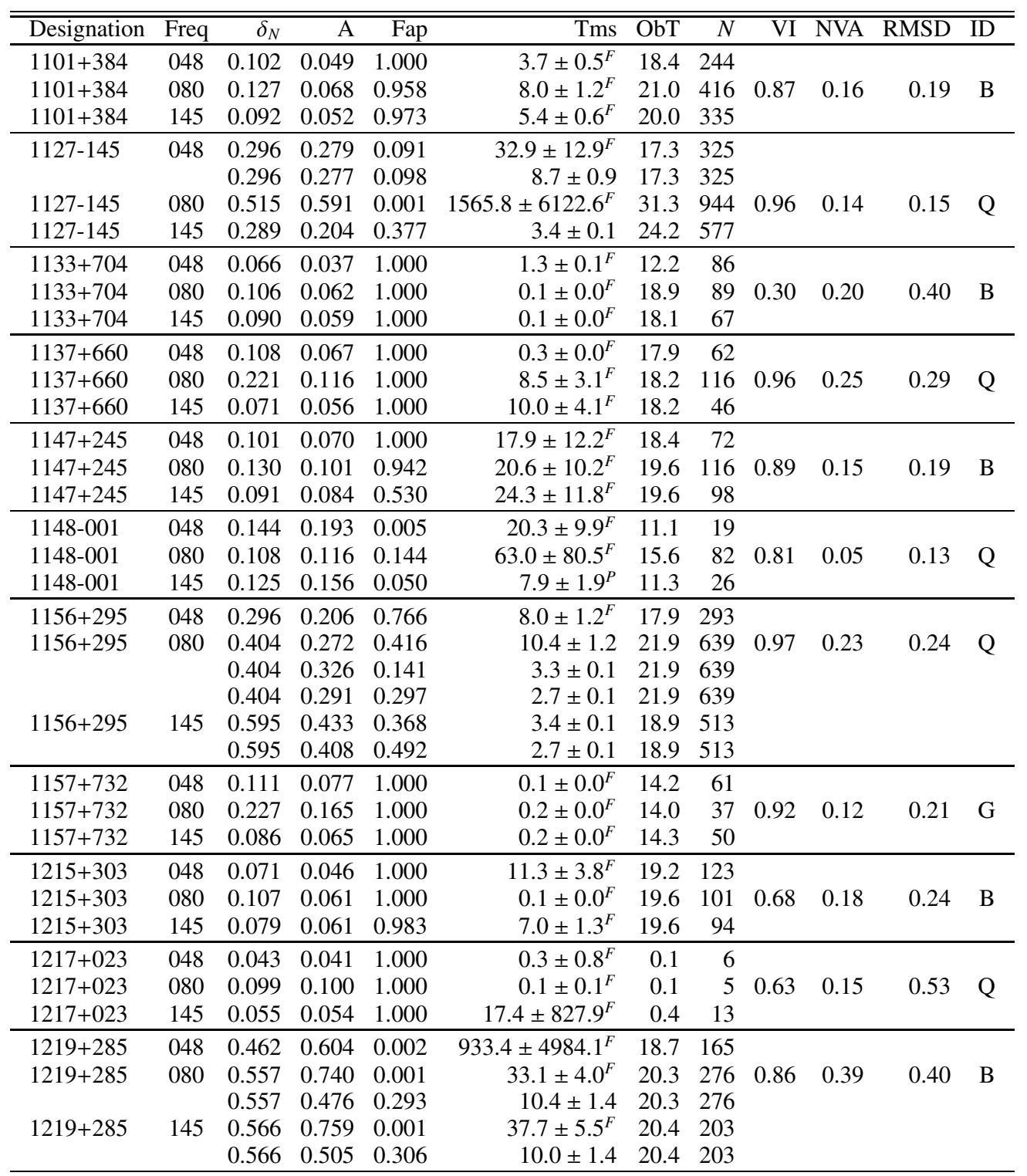


J. H. Fan et al.: Radio variability properties for radio sources, Online Material $p 11$

Table 1. continued.

\begin{tabular}{|c|c|c|c|c|c|c|c|c|c|c|c|}
\hline Designation & Freq & $\delta_{N}$ & A & Fap & Tms & ObT & $N$ & $\overline{\mathrm{VI}}$ & NVA & RMSD & ID \\
\hline $1222+216$ & 048 & 0.201 & 0.220 & 0.914 & $2.4 \pm 3.4^{F}$ & 1.3 & 12 & & & & \\
\hline $1222+216$ & 080 & 0.248 & 0.279 & 0.261 & $2.7 \pm 1.6^{F}$ & 2.2 & 28 & 0.96 & 0.11 & 0.22 & Q \\
\hline $1222+216$ & 145 & 0.345 & 0.411 & 0.046 & $2.6 \pm 0.5^{P}$ & 3.5 & 57 & & & & \\
\hline $1225+206$ & 048 & 0.088 & 0.052 & 1.000 & $0.2 \pm 0.0^{F}$ & 17.8 & 55 & & & & \\
\hline $1225+206$ & 080 & 0.090 & 0.052 & 1.000 & $0.2 \pm 0.0^{F}$ & 19.6 & 88 & 0.55 & 0.23 & 0.32 & Q \\
\hline $1225+206$ & 145 & 0.034 & 0.020 & 1.000 & $64.0 \pm 170.7^{F}$ & 19.6 & 78 & & & & \\
\hline $1226+023$ & 048 & 3.004 & 3.623 & 0.001 & $8.8 \pm 0.3$ & 21.0 & 493 & & & & \\
\hline \multirow[t]{3}{*}{$1226+023$} & 080 & 5.603 & 3.982 & 0.118 & $53.1 \pm 13.3^{F}$ & 33.8 & 1294 & 0.97 & 0.14 & 0.15 & Q \\
\hline & & 5.603 & 4.060 & 0.104 & $19.3 \pm 1.7$ & 33.8 & 1294 & & & & \\
\hline & & 5.603 & 5.591 & 0.006 & $8.3 \pm 0.2$ & 33.8 & 1294 & & & & \\
\hline $1226+023$ & 145 & 7.863 & 9.638 & 0.001 & $8.2 \pm 0.2$ & 25.0 & 760 & & & & \\
\hline $1253-055$ & 048 & 1.631 & 1.789 & 0.006 & $1051.2 \pm 6065.5^{F}$ & 21.0 & 551 & & & & \\
\hline \multirow[t]{5}{*}{$1253-055$} & 080 & 3.690 & 4.248 & 0.001 & $1684.3 \pm 5795.8^{F}$ & 33.7 & 1194 & 0.95 & 0.27 & 0.27 & Q \\
\hline & & 3.690 & 2.134 & 0.352 & $15.1 \pm 1.5$ & 33.7 & 1194 & & & & \\
\hline & & 3.690 & 2.014 & 0.426 & $10.1 \pm 0.7$ & 33.7 & 1194 & & & & \\
\hline & & 3.690 & 2.213 & 0.307 & $7.4 \pm 0.3$ & 33.7 & 1194 & & & & \\
\hline & & 3.690 & 2.126 & 0.357 & $5.1 \pm 0.2$ & 33.7 & 1194 & & & & \\
\hline $1253-055$ & 145 & 5.683 & 7.513 & 0.000 & $1248.4 \pm 2834.4^{F}$ & 25.0 & 779 & & & & \\
\hline $1254+476$ & 048 & 0.074 & 0.052 & 1.000 & $0.2 \pm 0.0^{F}$ & 14.2 & 57 & & & & \\
\hline $1254+476$ & 080 & 0.153 & 0.109 & 1.000 & $0.3 \pm 0.0^{F}$ & 14.0 & 60 & 0.89 & 0.13 & 0.19 & G \\
\hline $1254+476$ & 145 & 0.041 & 0.027 & 1.000 & $700.7 \pm 29886.7^{F}$ & 14.0 & 57 & & & & \\
\hline $1307+121$ & 048 & 0.168 & 0.213 & 0.016 & $22.3 \pm 6.1^{F}$ & 18.4 & 55 & & & & \\
\hline $1307+121$ & 080 & 0.245 & 0.309 & 0.007 & $22.3 \pm 4.0^{F}$ & 20.7 & 102 & 0.88 & 0.22 & 0.25 & B \\
\hline $1307+121$ & 145 & 0.232 & 0.306 & 0.002 & $20.6 \pm 2.6^{F}$ & 19.6 & 108 & & & & \\
\hline \multirow[t]{2}{*}{$1308+326$} & 048 & 0.762 & 0.826 & 0.008 & $19.2 \pm 2.2^{P}$ & 20.7 & 523 & & & & \\
\hline & & 0.762 & 0.718 & 0.045 & $11.8 \pm 1.1$ & 20.7 & 523 & & & & \\
\hline \multirow[t]{3}{*}{$1308+326$} & 080 & 0.772 & 0.587 & 0.115 & $22.4 \pm 3.7^{P}$ & 22.8 & 975 & 0.93 & 0.29 & 0.29 & B \\
\hline & & 0.772 & 0.569 & 0.143 & $9.7 \pm 0.7$ & 22.8 & 975 & & & & \\
\hline & & 0.772 & 0.439 & 0.476 & $5.9 \pm 0.4$ & 22.8 & 975 & & & & \\
\hline $1308+326$ & 145 & 0.799 & 0.744 & 0.028 & $8.5 \pm 0.4$ & 22.7 & 782 & & & & \\
\hline $1328+307$ & 048 & 0.078 & 0.021 & 1.000 & $8.2 \pm 2.5^{F}$ & 19.2 & 571 & & & & \\
\hline $1328+307$ & 080 & 0.102 & 0.074 & 0.223 & $33.4 \pm 8.4^{F}$ & 26.9 & 741 & 0.94 & 0.01 & 0.04 & Q \\
\hline $1328+307$ & 145 & 0.091 & 0.034 & 0.813 & $10.4 \pm 1.5^{F}$ & 24.5 & 1273 & & & & \\
\hline $1335-127$ & 048 & 0.823 & 0.922 & 0.009 & $8.0 \pm 0.5$ & 19.2 & 348 & & & & \\
\hline \multirow{2}{*}{$1335-127$} & 080 & 1.208 & 1.186 & 0.017 & $8.2 \pm 0.4$ & 24.6 & 723 & 0.98 & 0.26 & 0.26 & Q \\
\hline & & 1.208 & 0.878 & 0.238 & $5.7 \pm 0.3$ & 24.6 & 723 & & & & \\
\hline $1335-127$ & 145 & 1.461 & 1.477 & 0.020 & $8.0 \pm 0.4$ & 23.6 & 516 & & & & \\
\hline
\end{tabular}


J. H. Fan et al.: Radio variability properties for radio sources, Online Material p 12

Table 1. continued.

\begin{tabular}{|c|c|c|c|c|c|c|c|c|c|c|c|}
\hline Designation & Freq & $\delta_{N}$ & $\overline{\mathrm{A}}$ & Fap & Tms & ObT & $\bar{N}$ & $\overline{\mathrm{VI}}$ & $\overline{\mathrm{NVA}}$ & RMSD & ID \\
\hline $1354-152$ & 048 & 0.122 & 0.158 & 0.556 & $0.1 \pm 0.0^{F}$ & 5.6 & 6 & \multirow{3}{*}{0.97} & \multirow{3}{*}{0.32} & \multirow{3}{*}{0.35} & \multirow{3}{*}{ Q } \\
\hline $1354-152$ & 080 & 0.578 & 0.735 & 0.016 & $19.1 \pm 5.3^{F}$ & 15.9 & 49 & & & & \\
\hline $1354-152$ & 145 & 0.532 & 0.724 & 0.010 & $5.7 \pm 0.5$ & 13.8 & 21 & & & & \\
\hline $1358+624$ & 048 & 0.077 & 0.040 & 1.000 & $814.5 \pm 27901.1^{F}$ & 16.3 & 153 & \multirow{3}{*}{0.96} & \multirow{3}{*}{0.09} & \multirow{3}{*}{0.13} & \multirow{3}{*}{ G } \\
\hline $1358+624$ & 080 & 0.129 & 0.059 & 1.000 & $0.1 \pm 0.0^{F}$ & 19.2 & 158 & & & & \\
\hline $1358+624$ & 145 & 0.054 & 0.023 & 1.000 & $0.3 \pm 0.0^{F}$ & 16.5 & 136 & & & & \\
\hline $1400+162$ & 048 & 0.069 & 0.042 & 1.000 & $1.0 \pm 0.0^{F}$ & 18.7 & 68 & \multirow{3}{*}{0.78} & \multirow{3}{*}{0.19} & \multirow{3}{*}{0.27} & \multirow{3}{*}{ B } \\
\hline $1400+162$ & 080 & 0.088 & 0.048 & 1.000 & $0.1 \pm 0.0^{F}$ & 19.5 & 96 & & & & \\
\hline $1400+162$ & 145 & 0.045 & 0.026 & 1.000 & $0.7 \pm 0.0^{F}$ & 20.4 & 94 & & & & \\
\hline $1409+524$ & 048 & 0.196 & 0.122 & 1.000 & $0.1 \pm 0.0^{F}$ & 14.2 & 50 & \multirow{3}{*}{0.95} & \multirow{3}{*}{0.03} & \multirow{3}{*}{0.15} & \multirow{3}{*}{ G } \\
\hline $1409+524$ & 080 & 0.144 & 0.085 & 1.000 & $0.2 \pm 0.0^{F}$ & 14.0 & 52 & & & & \\
\hline $1409+524$ & 145 & 0.099 & 0.069 & 1.000 & $713.8 \pm 26000.2^{F}$ & 14.3 & 67 & & & & \\
\hline $1413+135$ & 048 & 0.174 & 0.148 & 0.351 & $929.6 \pm 13084.3^{F}$ & 18.6 & 250 & \multirow{5}{*}{0.95} & \multirow{5}{*}{0.25} & \multirow{5}{*}{0.25} & \multirow{5}{*}{ B } \\
\hline & & 0.174 & 0.164 & 0.143 & $8.2 \pm 0.9$ & 18.6 & 250 & & & & \\
\hline $1413+135$ & 080 & 0.377 & 0.377 & 0.016 & $8.2 \pm 0.4$ & 21.0 & 666 & & & & \\
\hline & & 0.377 & 0.272 & 0.281 & $4.8 \pm 0.2$ & 21.0 & 666 & & & & \\
\hline $1413+135$ & 145 & 0.672 & 0.625 & 0.053 & $9.4 \pm 0.8$ & 18.8 & 521 & & & & \\
\hline $1418+546$ & 048 & 0.395 & 0.392 & 0.049 & $961.1 \pm 8879.8^{F}$ & 19.2 & 334 & \multirow{6}{*}{0.92} & \multirow{6}{*}{0.29} & \multirow{6}{*}{0.30} & \multirow{6}{*}{ B } \\
\hline & & 0.395 & 0.318 & 0.349 & $9.4 \pm 1.2$ & 19.2 & 334 & & & & \\
\hline $1418+546$ & 080 & 0.541 & 0.459 & 0.110 & $1032.1 \pm 9566.1^{F}$ & 20.6 & 577 & & & & \\
\hline & & 0.541 & 0.389 & 0.341 & $11.3 \pm 1.4$ & 20.6 & 577 & & & & \\
\hline & & 0.541 & 0.419 & 0.218 & $2.5 \pm 0.1$ & 20.6 & 577 & & & & \\
\hline $1418+546$ & 145 & 0.589 & 0.570 & 0.034 & $997.0 \pm 7750.7^{F}$ & 19.9 & 520 & & & & \\
\hline $1458+718$ & 048 & 0.156 & 0.131 & 0.981 & $711.0 \pm 20868.1^{F}$ & 14.2 & 59 & \multirow{4}{*}{0.95} & & & \\
\hline $1458+718$ & 080 & 0.396 & 0.443 & 0.173 & $12.9 \pm 2.4$ & 26.9 & 44 & & 0.16 & 0.22 & $\mathrm{Q}$ \\
\hline $1458+718$ & 145 & 0.428 & 0.532 & 0.025 & $16.7 \pm 5.0^{F}$ & 14.3 & 51 & & & & \\
\hline & & 0.428 & 0.456 & 0.275 & $0.2 \pm 0.0$ & 14.3 & 51 & & & & \\
\hline $1504-166$ & 048 & 0.313 & 0.393 & 0.012 & $29.2 \pm 11.6^{F}$ & 14.6 & 76 & & & & \\
\hline $1504-166$ & 080 & 0.330 & 0.396 & 0.008 & $20.7 \pm 3.1^{P}$ & 21.7 & 170 & 0.97 & 0.11 & 0.14 & Q \\
\hline $1504-166$ & 145 & 0.325 & 0.382 & 0.026 & $19.1 \pm 5.0^{F}$ & 16.4 & 99 & & & & \\
\hline $1510-089$ & 048 & 0.683 & 0.622 & 0.084 & $12.9 \pm 1.6$ & 20.1 & 437 & & & & \\
\hline $1510-089$ & 080 & 0.816 & 0.596 & 0.177 & $12.3 \pm 1.2$ & 24.6 & 874 & 0.93 & 0.30 & 0.31 & Q \\
\hline $1510-089$ & 145 & 1.035 & 0.948 & 0.042 & $12.9 \pm 1.0$ & 24.7 & 671 & & & & \\
\hline $1514+197$ & 048 & 0.169 & 0.161 & 0.519 & $22.3 \pm 10.9^{F}$ & 18.7 & 79 & & & & \\
\hline $1514+197$ & 080 & 0.206 & 0.213 & 0.161 & $20.7 \pm 6.2^{P}$ & 20.8 & 104 & 0.76 & 0.37 & 0.40 & B \\
\hline $1514+197$ & 145 & 0.212 & 0.240 & 0.067 & $24.3 \pm 8.6^{F}$ & 19.0 & 82 & & & & \\
\hline
\end{tabular}


J. H. Fan et al.: Radio variability properties for radio sources, Online Material p 13

Table 1. continued.

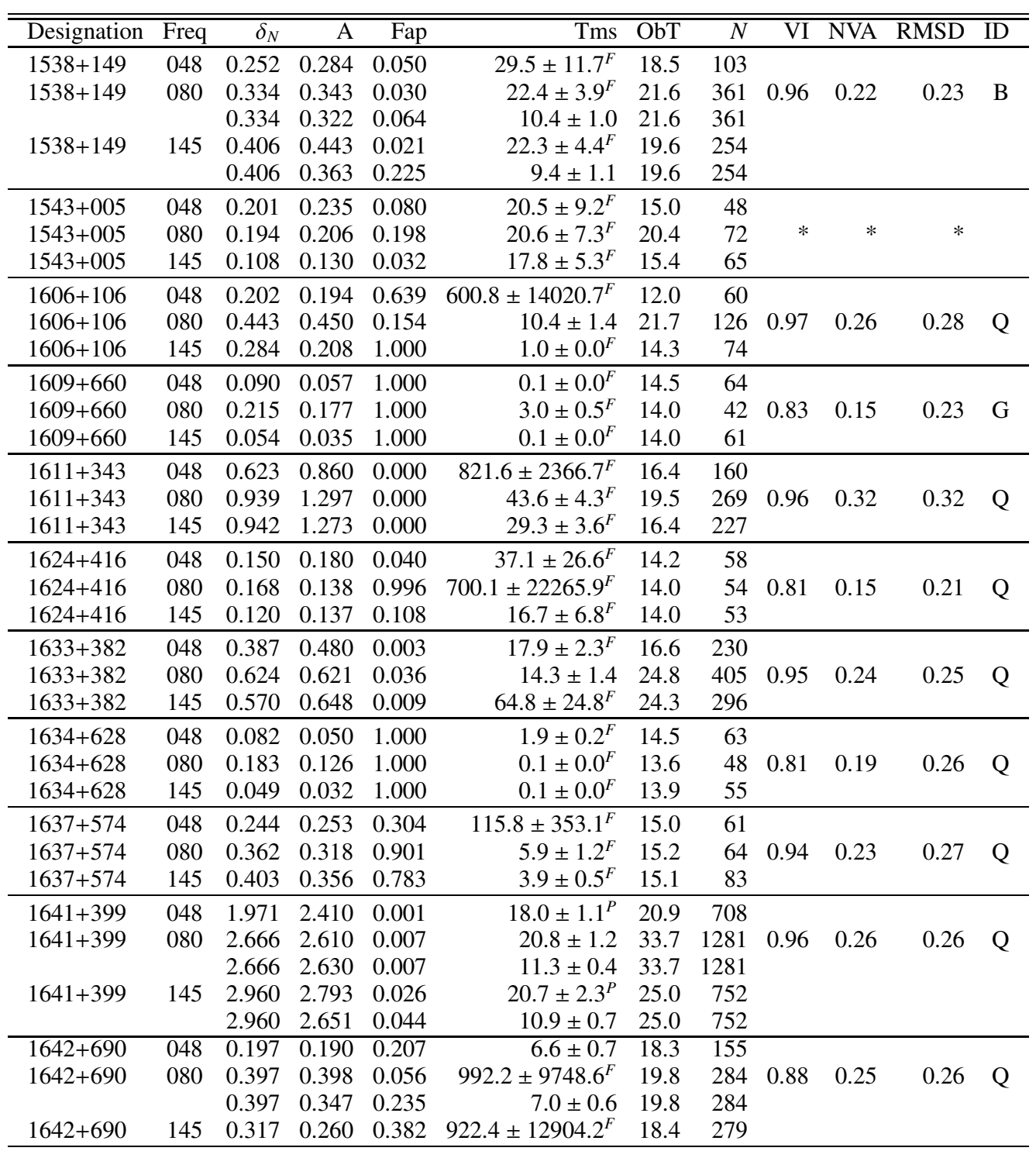


J. H. Fan et al.: Radio variability properties for radio sources, Online Material p 14

Table 1. continued.

\begin{tabular}{|c|c|c|c|c|c|c|c|c|c|c|c|}
\hline Designation & Freq & $\delta_{N}$ & $\overline{\mathrm{A}}$ & Fap & Tms & $\overline{\mathrm{ObT}}$ & $\bar{N}$ & $\overline{\mathrm{VI}}$ & $\overline{\mathrm{NVA}}$ & RMSD & ID \\
\hline \multirow[t]{2}{*}{$1652+398$} & 048 & 0.150 & 0.158 & 0.052 & $933.4 \pm 9878.5^{F}$ & 18.7 & 202 & & & & \\
\hline & & 0.150 & 0.155 & 0.065 & $11.8 \pm 1.6$ & 18.7 & 202 & & & & \\
\hline \multirow[t]{3}{*}{$1652+398$} & 080 & 0.186 & 0.199 & 0.012 & $1064.2 \pm 7297.2^{F}$ & 21.3 & 440 & 0.98 & 0.13 & 0.15 & B \\
\hline & & 0.186 & 0.181 & 0.040 & $12.3 \pm 1.2$ & 21.3 & 440 & & & & \\
\hline & & 0.186 & 0.146 & 0.288 & $7.4 \pm 0.6$ & 21.3 & 440 & & & & \\
\hline \multirow[t]{3}{*}{$1652+398$} & 145 & 0.151 & 0.169 & 0.015 & $1001.3 \pm 8145.9^{F}$ & 20.0 & 253 & & & & \\
\hline & & 0.151 & 0.158 & 0.038 & $11.8 \pm 1.3$ & 20.0 & 253 & & & & \\
\hline & & 0.151 & 0.133 & 0.256 & $6.8 \pm 0.6$ & 20.0 & 253 & & & & \\
\hline $1717+178$ & 048 & 0.188 & 0.163 & 0.897 & $7.0 \pm 1.3^{F}$ & 18.7 & 73 & & & & \\
\hline $1717+178$ & 080 & 0.209 & 0.201 & 0.296 & $6.8 \pm 0.7$ & 21.6 & 119 & 0.92 & 0.27 & 0.30 & B \\
\hline $1717+178$ & 145 & 0.195 & 0.199 & 0.237 & $7.0 \pm 0.9$ & 17.9 & 89 & & & & \\
\hline $1721+343$ & 048 & 0.058 & 0.038 & 1.000 & $0.2 \pm 0.0^{F}$ & 10.7 & 49 & & & & \\
\hline $1721+343$ & 080 & 0.122 & 0.084 & 1.000 & $3.4 \pm 0.9^{F}$ & 10.3 & 52 & 0.74 & 0.22 & 0.28 & Q \\
\hline $1721+343$ & 145 & 0.051 & 0.039 & 1.000 & $0.1 \pm 0.0^{F}$ & 11.0 & 49 & & & & \\
\hline $1727+502$ & 048 & 0.068 & 0.037 & 1.000 & $0.1 \pm 0.0^{F}$ & 18.7 & 75 & & & & \\
\hline $1727+502$ & 080 & 0.094 & 0.043 & 1.000 & $982.4 \pm 45349.6^{F}$ & 19.6 & 109 & 0.87 & 0.31 & 0.47 & B \\
\hline $1727+502$ & 145 & 0.037 & 0.020 & 1.000 & $0.3 \pm 0.0^{F}$ & 19.4 & 85 & & & & \\
\hline \multirow[t]{3}{*}{$1730-130$} & 048 & 1.047 & 0.839 & 0.413 & $10.1 \pm 1.4$ & 21.0 & 295 & & & & \\
\hline & & 1.047 & 0.955 & 0.148 & $6.3 \pm 0.4$ & 21.0 & 295 & & & & \\
\hline & & 1.047 & 0.869 & 0.326 & $5.0 \pm 0.3$ & 21.0 & 295 & & & & \\
\hline \multirow[t]{3}{*}{$1730-130$} & 080 & 1.903 & 1.782 & 0.028 & $53.0 \pm 12.1^{F}$ & 32.0 & 748 & 0.96 & 0.31 & 0.31 & Q \\
\hline & & 1.903 & 1.444 & 0.172 & $10.1 \pm 0.6$ & 32.0 & 748 & & & & \\
\hline & & 1.903 & 1.604 & 0.078 & $6.3 \pm 0.2$ & 32.0 & 748 & & & & \\
\hline \multirow[t]{3}{*}{$1730-130$} & 145 & 2.470 & 1.876 & 0.311 & $33.3 \pm 10.9^{F}$ & 24.2 & 486 & & & & \\
\hline & & 2.470 & 1.804 & 0.388 & $10.1 \pm 1.0$ & 24.2 & 486 & & & & \\
\hline & & 2.470 & 1.993 & 0.208 & $6.1 \pm 0.3$ & 24.2 & 486 & & & & \\
\hline \multirow[t]{2}{*}{ 1741-038 } & 048 & 0.890 & 1.179 & 0.002 & $549.9 \pm 3239.2^{F}$ & 11.0 & 112 & & & & \\
\hline & & 0.890 & 1.088 & 0.011 & $8.2 \pm 1.1^{P}$ & 11.0 & 112 & & & & \\
\hline \multirow[t]{3}{*}{$1741-038$} & 080 & 1.139 & 1.437 & 0.004 & $1209.3 \pm 8200.4^{F}$ & 24.2 & 155 & 0.96 & 0.29 & 0.30 & Q \\
\hline & & 1.139 & 1.478 & 0.002 & $18.0 \pm 1.6^{P}$ & 24.2 & 155 & & & & \\
\hline & & 1.139 & 1.124 & 0.166 & $6.5 \pm 0.5$ & 24.2 & 155 & & & & \\
\hline \multirow[t]{2}{*}{$1741-038$} & 145 & 1.263 & 1.413 & 0.018 & $14.1 \pm 3.0^{F}$ & 11.6 & 219 & & & & \\
\hline & & 1.263 & 1.324 & 0.047 & $5.8 \pm 0.6$ & 11.6 & 219 & & & & \\
\hline \multirow[t]{2}{*}{$1749+096$} & 048 & 0.582 & 0.425 & 0.377 & $10.4 \pm 1.4$ & 19.2 & 500 & & & & \\
\hline & & 0.582 & 0.440 & 0.308 & $6.3 \pm 0.5$ & 19.2 & 500 & & & & \\
\hline \multirow[t]{2}{*}{$1749+096$} & 080 & 0.970 & 0.640 & 0.309 & $9.0 \pm 0.9$ & 19.8 & 866 & 0.96 & 0.38 & 0.38 & B \\
\hline & & 0.970 & 0.738 & 0.137 & $6.8 \pm 0.4$ & 19.8 & 866 & & & & \\
\hline $1749+096$ & 145 & 1.413 & 0.861 & 0.536 & $3.1 \pm 0.1^{F}$ & 20.4 & 713 & & & & \\
\hline
\end{tabular}


J. H. Fan et al.: Radio variability properties for radio sources, Online Material p 15

Table 1. continued.

\begin{tabular}{|c|c|c|c|c|c|c|c|c|c|c|c|}
\hline Designation & Freq & $\delta_{N}$ & $\overline{\mathrm{A}}$ & Fap & Tms & ObT & $\bar{N}$ & VI & $\overline{\text { NVA }}$ & RMSD & $\overline{\mathrm{ID}}$ \\
\hline $1749+701$ & 048 & 0.281 & 0.323 & 0.015 & $29.5 \pm 8.0^{F}$ & 18.7 & 193 & & & & \\
\hline \multirow[t]{2}{*}{$1749+701$} & 080 & 0.335 & 0.365 & 0.018 & $22.3 \pm 4.2^{F}$ & 19.2 & 292 & 0.67 & 0.33 & 0.35 & B \\
\hline & & 0.335 & 0.330 & 0.067 & $12.3 \pm 1.6$ & 19.2 & 292 & & & & \\
\hline $1749+701$ & 145 & 0.232 & 0.249 & 0.029 & $950.8 \pm 8743.0^{F}$ & 19.0 & 243 & & & & \\
\hline \multirow[t]{2}{*}{$1803+784$} & 048 & 0.342 & 0.298 & 0.329 & $11.3 \pm 2.0$ & 18.1 & 220 & & & & \\
\hline & & 0.342 & 0.289 & 0.418 & $7.8 \pm 1.0$ & 18.1 & 220 & \multirow{3}{*}{0.97} & \multirow{3}{*}{0.13} & \multirow{3}{*}{0.15} & \multirow{3}{*}{ B } \\
\hline $1803+784$ & 080 & 0.409 & 0.236 & 0.997 & $1.4 \pm 0.1^{F}$ & 18.0 & 233 & & & & \\
\hline $1803+784$ & 145 & 0.411 & 0.369 & 0.121 & $7.0 \pm 0.6$ & 18.1 & 381 & & & & \\
\hline $1807+698$ & 048 & 0.145 & 0.143 & 0.119 & $933.5 \pm 11424.7^{F}$ & 18.7 & 196 & \multirow{3}{*}{0.95} & \multirow{3}{*}{0.08} & \multirow{3}{*}{0.11} & \multirow{3}{*}{ B } \\
\hline $1807+698$ & 080 & 0.192 & 0.128 & 0.702 & $991.5 \pm 15563.9^{F}$ & 19.8 & 394 & & & & \\
\hline $1807+698$ & 145 & 0.189 & 0.125 & 0.879 & $977.5 \pm 18228.0^{F}$ & 19.6 & 285 & & & & \\
\hline $1817-162$ & 048 & 7.220 & 5.588 & 1.000 & $0.1 \pm 0.2^{F}$ & 0.2 & 6 & \multirow{3}{*}{ * } & & \multirow{3}{*}{$*$} & \\
\hline $1817-162$ & 080 & 4.672 & 5.629 & 0.230 & $0.2 \pm 0.1^{P}$ & 0.2 & 14 & & * & & \\
\hline $1817-162$ & 145 & 27.765 & 30.727 & 1.000 & $0.1 \pm 0.1^{F}$ & 0.2 & 7 & & & & \\
\hline $1823+568$ & 048 & 0.169 & 0.181 & 0.107 & $14.9 \pm 4.0^{P}$ & 15.9 & 101 & \multirow{4}{*}{0.91} & \multirow{4}{*}{0.19} & \multirow{4}{*}{0.21} & \multirow{4}{*}{ B } \\
\hline $1823+568$ & 080 & 0.280 & 0.252 & 0.270 & $24.2 \pm 9.5^{F}$ & 17.1 & 209 & & & & \\
\hline \multirow[t]{2}{*}{$1823+568$} & 145 & 0.400 & 0.445 & 0.016 & $19.1 \pm 3.4^{F}$ & 17.7 & 253 & & & & \\
\hline & & 0.400 & 0.361 & 0.204 & $8.8 \pm 1.1$ & 17.7 & 253 & & & & \\
\hline $1828+487$ & 048 & 0.332 & 0.392 & 0.042 & $14.1 \pm 3.7^{P}$ & 14.5 & 68 & \multirow{4}{*}{0.96} & \multirow{4}{*}{0.08} & \multirow{4}{*}{0.14} & \multirow{4}{*}{ Q } \\
\hline \multirow[t]{2}{*}{$1828+487$} & 080 & 0.390 & 0.398 & 0.296 & $22.5 \pm 6.1^{P}$ & 30.7 & 75 & & & & \\
\hline & & 0.390 & 0.426 & 0.125 & $10.9 \pm 1.2$ & 30.7 & 75 & & & & \\
\hline $1828+487$ & 145 & 0.466 & 0.487 & 0.130 & $10.4 \pm 1.3$ & 24.6 & 112 & & & & \\
\hline $1842+455$ & 048 & 0.090 & 0.063 & 1.000 & $0.1 \pm 0.0^{F}$ & 14.5 & 54 & \multirow{3}{*}{0.94} & & & \\
\hline $1842+455$ & 080 & 0.127 & 0.077 & 1.000 & $0.2 \pm 0.0^{F}$ & 13.8 & 50 & & 0.09 & 0.18 & G \\
\hline $1842+455$ & 145 & 0.059 & 0.036 & 1.000 & $0.3 \pm 0.0^{F}$ & 14.3 & 62 & & & & \\
\hline $1845+797$ & 048 & 0.177 & 0.168 & 0.596 & $7.3 \pm 1.6^{F}$ & 14.7 & 71 & & & & \\
\hline $1845+797$ & 080 & 0.359 & 0.328 & 0.645 & $10.4 \pm 2.1^{F}$ & 21.6 & 87 & 0.91 & 0.12 & 0.16 & G \\
\hline $1845+797$ & 145 & 0.250 & 0.211 & 0.707 & $8.2 \pm 1.2^{F}$ & 21.6 & 130 & & & & \\
\hline $1901+319$ & 048 & 0.264 & 0.308 & 0.016 & $15.8 \pm 2.8^{P}$ & 16.4 & 157 & & & & \\
\hline $1901+319$ & 080 & 0.232 & 0.242 & 0.041 & $20.7 \pm 3.4^{P}$ & 24.8 & 242 & 0.88 & 0.12 & 0.15 & Q \\
\hline $1901+319$ & 145 & 0.169 & 0.131 & 0.851 & $4.1 \pm 0.4^{F}$ & 16.5 & 159 & & & & \\
\hline $1921-293$ & 048 & 2.977 & 3.485 & 0.005 & $22.3 \pm 3.1^{F}$ & 19.9 & 332 & & & & \\
\hline $1921-293$ & 080 & 3.510 & 3.478 & 0.017 & $52.5 \pm 14.6^{F}$ & 24.6 & 677 & 0.97 & 0.30 & 0.30 & Q \\
\hline $1921-293$ & 145 & 4.213 & 3.750 & 0.069 & $22.4 \pm 3.7^{P}$ & 23.3 & 585 & & & & \\
\hline $1928+738$ & 048 & 0.326 & 0.399 & 0.004 & $116.6 \pm 110.1^{F}$ & 15.7 & 233 & & & & \\
\hline $1928+738$ & 080 & 0.470 & 0.555 & 0.009 & $29.5 \pm 7.5^{F}$ & 18.1 & 197 & 0.96 & 0.13 & 0.15 & Q \\
\hline & & 0.470 & 0.402 & 0.437 & $8.2 \pm 1.2$ & 18.1 & 197 & & & & \\
\hline $1928+738$ & 145 & 0.519 & 0.579 & 0.009 & $62.9 \pm 35.7^{F}$ & 15.5 & 349 & & & & \\
\hline & & 0.519 & 0.421 & 0.313 & $7.7 \pm 1.0$ & 15.5 & 349 & & & & \\
\hline
\end{tabular}


J. H. Fan et al.: Radio variability properties for radio sources, Online Material p 16

Table 1. continued.

\begin{tabular}{|c|c|c|c|c|c|c|c|c|c|c|c|}
\hline Designation & Freq & $\delta_{N}$ & $\mathrm{~A}$ & Fap & Tms & ObT & $\bar{N}$ & VI & $\overline{\text { NVA }}$ & RMSD & ID \\
\hline $1939+605$ & 048 & 0.066 & 0.044 & 1.000 & $0.3 \pm 0.0^{F}$ & 13.9 & 55 & & & & \\
\hline $1939+605$ & 080 & 0.142 & 0.101 & 1.000 & $13.4 \pm 10.5^{F}$ & 13.7 & 51 & 0.94 & 0.13 & 0.21 & G \\
\hline $1939+605$ & 145 & 0.041 & 0.026 & 1.000 & $0.1 \pm 0.0^{F}$ & 14.3 & 63 & & & & \\
\hline $1951+498$ & 048 & 0.056 & 0.037 & 1.000 & $0.1 \pm 0.0^{F}$ & 11.0 & 47 & & & & \\
\hline $1951+498$ & 080 & 0.131 & 0.083 & 1.000 & $5.5 \pm 2.5^{F}$ & 11.1 & 52 & 0.71 & 0.48 & 0.58 & Q \\
\hline $1951+498$ & 145 & 0.044 & 0.028 & 1.000 & $0.3 \pm 0.0^{F}$ & 11.0 & 45 & & & & \\
\hline $1954+513$ & 048 & 0.187 & 0.168 & 0.883 & $747.0 \pm 19864.3^{F}$ & 15.0 & 58 & & & & \\
\hline $1954+513$ & 080 & 0.338 & 0.393 & 0.052 & $20.6 \pm 6.2^{F}$ & 19.0 & 71 & 0.92 & 0.21 & 0.24 & Q \\
\hline $1954+513$ & 145 & 0.295 & 0.336 & 0.084 & $22.3 \pm 8.2^{F}$ & 18.8 & 62 & & & & \\
\hline $2005+403$ & 048 & 0.719 & 0.960 & 0.001 & $26.6 \pm 2.9^{F}$ & 18.4 & 242 & & & & \\
\hline $2005+403$ & 080 & 0.921 & 1.055 & 0.003 & $1171.4 \pm 6187.4^{F}$ & 23.4 & 522 & 0.98 & 0.21 & 0.22 & Q \\
\hline $2005+403$ & 145 & 0.721 & 0.915 & 0.001 & $1188.3 \pm 4289.8^{F}$ & 23.8 & 517 & & & & \\
\hline $2007+777$ & 048 & 0.409 & 0.332 & 0.622 & $3.7 \pm 0.3^{F}$ & 16.0 & 186 & & & & \\
\hline $2007+777$ & 080 & 0.432 & 0.358 & 0.407 & $2.9 \pm 0.1$ & 17.9 & 252 & 0.95 & 0.23 & 0.24 & B \\
\hline $2007+777$ & 145 & 0.649 & 0.621 & 0.058 & $12.8 \pm 1.8^{P}$ & 16.7 & 395 & & & & \\
\hline $2014+370$ & 048 & 0.474 & 0.598 & 0.023 & $11.2 \pm 2.9^{F}$ & 11.0 & 44 & & & & \\
\hline $2014+370$ & 080 & 0.135 & 0.083 & 1.000 & $0.4 \pm 0.0^{F}$ & 15.3 & 56 & * & $*$ & * & \\
\hline $2014+370$ & 145 & 0.085 & 0.056 & 1.000 & $768.4 \pm 30371.9^{F}$ & 15.4 & 64 & & & & \\
\hline $2020+614$ & 048 & 0.178 & 0.230 & 0.009 & $723.6 \pm 7065.9^{F}$ & 14.5 & 56 & & & & \\
\hline $2020+614$ & 080 & 0.433 & 0.556 & 0.012 & $52.5 \pm 23.6^{F}$ & 24.7 & 52 & 0.93 & 0.14 & 0.20 & G \\
\hline $2020+614$ & 145 & 0.385 & 0.464 & 0.032 & $714.0 \pm 9166.0^{F}$ & 14.3 & 63 & & & & \\
\hline $2032+107$ & 048 & 0.149 & 0.095 & 1.000 & $12.9 \pm 7.7^{F}$ & 18.4 & 59 & & & & \\
\hline $2032+107$ & 080 & 0.211 & 0.143 & 1.000 & $0.2 \pm 0.0^{F}$ & 20.5 & 97 & 0.91 & 0.30 & 0.33 & B \\
\hline $2032+107$ & 145 & 0.222 & 0.142 & 1.000 & $0.1 \pm 0.0^{F}$ & 17.1 & 68 & & & & \\
\hline $2037+421$ & 048 & 0.604 & 0.544 & 1.000 & $0.1 \pm 0.1^{F}$ & 0.2 & 9 & & & & \\
\hline $2037+421$ & 080 & 0.315 & 0.239 & 1.000 & $0.1 \pm 0.1^{F}$ & 0.2 & 12 & * & * & * & \\
\hline $2037+421$ & 145 & 0.399 & 0.320 & 1.000 & $0.1 \pm 0.0^{F}$ & 0.3 & 15 & & & & \\
\hline $2121+053$ & 048 & 1.166 & 1.224 & 0.060 & $6.8 \pm 0.6$ & 18.5 & 185 & & & & \\
\hline $2121+053$ & 080 & 1.337 & 1.520 & 0.003 & $6.8 \pm 0.2$ & 22.8 & 590 & 0.97 & 0.48 & 0.48 & Q \\
\hline \multirow{2}{*}{$2121+053$} & 145 & 1.071 & 1.129 & 0.021 & $7.0 \pm 0.4$ & 20.1 & 349 & & & & \\
\hline & & 1.071 & 0.907 & 0.228 & $4.9 \pm 0.3$ & 20.1 & 349 & & & & \\
\hline \multirow[t]{3}{*}{ 2131-021 } & 048 & 0.558 & 0.664 & 0.023 & $933.4 \pm 10301.7^{F}$ & 18.7 & 94 & & & & \\
\hline & & 0.558 & 0.612 & 0.085 & $12.9 \pm 2.5^{P}$ & 18.7 & 94 & & & & \\
\hline & & 0.558 & 0.623 & 0.066 & $9.7 \pm 1.3$ & 18.7 & 94 & & & & \\
\hline \multirow[t]{3}{*}{$2131-021$} & 080 & 0.734 & 0.685 & 0.144 & $29.7 \pm 8.6^{F}$ & 24.1 & 261 & 0.97 & 0.32 & 0.32 & B \\
\hline & & 0.734 & 0.842 & 0.009 & $9.7 \pm 0.6$ & 24.1 & 261 & & & & \\
\hline & & 0.734 & 0.724 & 0.078 & $6.3 \pm 0.4$ & 24.1 & 261 & & & & \\
\hline \multirow[t]{3}{*}{ 2131-021 } & 145 & 0.685 & 0.668 & 0.082 & $948.5 \pm 9967.8^{F}$ & 19.0 & 278 & & & & \\
\hline & & 0.685 & 0.864 & 0.002 & $10.0 \pm 0.5$ & 19.0 & 278 & & & & \\
\hline & & 0.685 & 0.662 & 0.090 & $5.9 \pm 0.4$ & 19.0 & 278 & & & & \\
\hline
\end{tabular}


J. H. Fan et al.: Radio variability properties for radio sources, Online Material p 17

Table 1. continued.

\begin{tabular}{|c|c|c|c|c|c|c|c|c|c|c|c|}
\hline Designation & Freq & $\delta_{N}$ & $\mathrm{~A}$ & Fap & Tms & ObT & $N$ & $\mathrm{VI}$ & NVA & RMSD & ID \\
\hline $2134+004$ & 048 & 0.521 & 0.680 & 0.001 & $20.6 \pm 1.9^{F}$ & 19.5 & 244 & \multirow{3}{*}{0.99} & \multirow{3}{*}{0.10} & \multirow{3}{*}{0.11} & \multirow{3}{*}{ Q } \\
\hline $2134+004$ & 080 & 0.946 & 1.195 & 0.000 & $86.3 \pm 16.1^{F}$ & 31.7 & 603 & & & & \\
\hline $2134+004$ & 145 & 0.588 & 0.564 & 0.044 & $1218.8 \pm 10105.0^{F}$ & 24.4 & 474 & & & & \\
\hline $2136+141$ & 048 & 0.246 & 0.324 & 0.012 & $522.6 \pm 5636.5^{F}$ & 10.5 & 36 & \multirow{3}{*}{0.89} & \multirow{3}{*}{0.27} & \multirow{3}{*}{0.31} & \multirow{3}{*}{ Q } \\
\hline $2136+141$ & 080 & 0.502 & 0.652 & 0.011 & $20.7 \pm 4.2^{P}$ & 21.0 & 49 & & & & \\
\hline $2136+141$ & 145 & 0.394 & 0.492 & 0.022 & $9.0 \pm 1.8^{P}$ & 11.0 & 50 & & & & \\
\hline $2145+067$ & 048 & 1.260 & 1.753 & 0.000 & $33.0 \pm 2.4^{F}$ & 18.2 & 242 & \multirow{5}{*}{0.97} & \multirow{5}{*}{0.38} & \multirow{5}{*}{0.38} & \multirow{5}{*}{ Q } \\
\hline $2145+067$ & 080 & 2.070 & 2.841 & 0.000 & $33.5 \pm 1.1^{F}$ & 31.5 & 740 & & & & \\
\hline & & 2.070 & 1.558 & 0.187 & $10.1 \pm 0.6$ & 31.5 & 740 & & & & \\
\hline $2145+067$ & 145 & 1.659 & 1.944 & 0.002 & $1001.3 \pm 4549.1^{F}$ & 20.0 & 614 & & & & \\
\hline & & 1.659 & 1.290 & 0.195 & $8.5 \pm 0.7$ & 20.0 & 614 & & & & \\
\hline $2153+377$ & 048 & 0.253 & 0.138 & 1.000 & $0.1 \pm 0.0^{F}$ & 14.5 & 49 & \multirow{3}{*}{0.89} & \multirow{3}{*}{0.14} & \multirow{3}{*}{0.21} & \multirow{3}{*}{ G } \\
\hline $2153+377$ & 080 & 0.143 & 0.102 & 1.000 & $0.3 \pm 0.0^{F}$ & 14.0 & 55 & & & & \\
\hline $2153+377$ & 145 & 0.053 & 0.030 & 1.000 & $0.1 \pm 0.0^{F}$ & 14.3 & 60 & & & & \\
\hline $2155-152$ & 048 & 0.502 & 0.600 & 0.038 & $26.6 \pm 10.1^{F}$ & 18.7 & 63 & \multirow{4}{*}{0.94} & \multirow{4}{*}{0.26} & \multirow{4}{*}{0.27} & \multirow{4}{*}{ Q } \\
\hline $2155-152$ & 080 & 0.571 & 0.615 & 0.035 & $29.5 \pm 8.7^{F}$ & 19.8 & 206 & & & & \\
\hline $2155-152$ & 145 & 0.471 & 0.480 & 0.172 & $43.6 \pm 30.0^{F}$ & 19.0 & 114 & & & & \\
\hline & & 0.471 & 0.496 & 0.116 & $5.3 \pm 0.4$ & 19.0 & 114 & & & & \\
\hline $2155-304$ & 048 & 0.127 & 0.081 & 1.000 & $0.3 \pm 0.0^{F}$ & 18.4 & 70 & \multirow{3}{*}{0.76} & \multirow{3}{*}{0.34} & \multirow{3}{*}{0.40} & \multirow{3}{*}{ B } \\
\hline $2155-304$ & 080 & 0.153 & 0.082 & 1.000 & $119.5 \pm 525.1^{F}$ & 18.7 & 140 & & & & \\
\hline $2155-304$ & 145 & 0.114 & 0.081 & 0.975 & $22.3 \pm 12.0^{F}$ & 19.4 & 148 & & & & \\
\hline $2200+420$ & 048 & 1.592 & 1.419 & 0.047 & $1064.1 \pm 8017.8^{F}$ & 21.3 & 741 & \multirow{9}{*}{0.95} & & & \\
\hline & & 1.592 & 1.532 & 0.021 & $7.8 \pm 0.4$ & 21.3 & 741 & & & & \\
\hline & & 1.592 & 0.995 & 0.471 & $3.9 \pm 0.2$ & 21.3 & 741 & & & & \\
\hline $2200+420$ & 080 & 2.292 & 1.781 & 0.072 & $52.9 \pm 13.2^{F}$ & 30.9 & 1208 & & 0.50 & 0.51 & B \\
\hline & & 2.292 & 1.180 & 0.496 & $9.1 \pm 0.7$ & 30.9 & 1208 & & & & \\
\hline & & 2.292 & 1.342 & 0.332 & $6.8 \pm 0.3$ & 30.9 & 1208 & & & & \\
\hline & & 2.292 & 1.524 & 0.189 & $3.8 \pm 0.1$ & 30.9 & 1208 & & & & \\
\hline $2200+420$ & 145 & 2.117 & 1.579 & 0.118 & $7.8 \pm 0.4$ & 24.7 & 1051 & & & & \\
\hline & & 2.117 & 1.280 & 0.350 & $3.9 \pm 0.1$ & 24.7 & 1051 & & & & \\
\hline $2202+315$ & 048 & 0.584 & 0.629 & 0.062 & $5.9 \pm 0.5$ & 17.1 & 142 & & & & \\
\hline $2202+315$ & 080 & 1.071 & 1.267 & 0.004 & $15.0 \pm 1.3^{P}$ & 20.8 & 321 & 0.97 & 0.32 & 0.33 & Q \\
\hline & & 1.071 & 0.960 & 0.158 & $6.3 \pm 0.4$ & 20.8 & 321 & & & & \\
\hline $2202+315$ & 145 & 1.053 & 1.246 & 0.008 & $16.8 \pm 2.6^{F}$ & 16.3 & 212 & & & & \\
\hline & & 1.053 & 0.873 & 0.490 & $5.8 \pm 0.6$ & 16.3 & 212 & & & & \\
\hline
\end{tabular}


J. H. Fan et al.: Radio variability properties for radio sources, Online Material p 18

Table 1. continued.

\begin{tabular}{|c|c|c|c|c|c|c|c|c|c|c|c|}
\hline Designation & Freq & $\overline{\delta_{N}}$ & $\mathrm{~A}$ & Fap & Tms & ObT & $\bar{N}$ & $\overline{\mathrm{VI}}$ & $\overline{\mathrm{NVA}}$ & RMSD & $\overline{\mathrm{ID}}$ \\
\hline \multirow[t]{2}{*}{$2223-052$} & 048 & 0.764 & 0.784 & 0.025 & $17.9 \pm 2.7^{P}$ & 19.0 & 406 & & & & \\
\hline & & 0.764 & 0.590 & 0.354 & $7.5 \pm 0.8$ & 19.0 & 406 & & & & \\
\hline \multirow[t]{2}{*}{$2223-052$} & 080 & 1.333 & 1.175 & 0.060 & $26.9 \pm 3.6^{P}$ & 31.8 & 686 & 0.96 & 0.26 & 0.27 & $\mathrm{Q}$ \\
\hline & & 1.333 & 1.143 & 0.077 & $7.2 \pm 0.3$ & 31.8 & 686 & & & & \\
\hline \multirow[t]{2}{*}{$2223-052$} & 145 & 1.632 & 1.200 & 0.285 & $19.2 \pm 4.2^{P}$ & 19.5 & 602 & & & & \\
\hline & & 1.632 & 1.420 & 0.082 & $6.5 \pm 0.4$ & 19.5 & 602 & & & & \\
\hline $2229+391$ & 048 & 0.104 & 0.072 & 1.000 & $0.2 \pm 0.0^{F}$ & 14.5 & 55 & & & & \\
\hline $2229+391$ & 080 & 0.104 & 0.078 & 1.000 & $0.1 \pm 0.0^{F}$ & 14.0 & 50 & 0.81 & 0.12 & 0.20 & G \\
\hline $2229+391$ & 145 & 0.031 & 0.021 & 1.000 & $0.2 \pm 0.0^{F}$ & 14.3 & 61 & & & & \\
\hline $2230+114$ & 048 & 0.344 & 0.333 & 0.077 & $882.2 \pm 8977.2^{F}$ & 17.6 & 305 & & & & \\
\hline \multirow[t]{2}{*}{$2230+114$} & 080 & 0.510 & 0.469 & 0.029 & $37.9 \pm 7.9^{F}$ & 24.7 & 821 & 0.98 & 0.14 & 0.14 & Q \\
\hline & & 0.510 & 0.376 & 0.182 & $8.2 \pm 0.5$ & 24.7 & 821 & & & & \\
\hline \multirow[t]{3}{*}{$2230+114$} & 145 & 0.759 & 0.813 & 0.006 & $974.0 \pm 5264.3^{F}$ & 19.5 & 708 & & & & \\
\hline & & 0.759 & 0.619 & 0.111 & $8.5 \pm 0.7$ & 19.5 & 708 & & & & \\
\hline & & 0.759 & 0.483 & 0.465 & $4.1 \pm 0.2$ & 19.5 & 708 & & & & \\
\hline $2243+394$ & 048 & 0.115 & 0.081 & 1.000 & $0.8 \pm 0.0^{F}$ & 14.5 & 45 & & & & \\
\hline $2243+394$ & 080 & 0.135 & 0.096 & 1.000 & $0.2 \pm 0.0^{F}$ & 13.6 & 53 & 0.87 & 0.06 & 0.16 & G \\
\hline $2243+394$ & 145 & 0.057 & 0.036 & 1.000 & $1.0 \pm 0.1^{F}$ & 14.3 & 56 & & & & \\
\hline \multirow[t]{2}{*}{$2251+158$} & 048 & 2.301 & 1.598 & 0.426 & $12.3 \pm 1.8$ & 20.9 & 554 & & & & \\
\hline & & 2.301 & 2.428 & 0.010 & $6.2 \pm 0.2$ & 20.9 & 554 & & & & \\
\hline \multirow[t]{4}{*}{$2251+158$} & 080 & 3.933 & 2.466 & 0.261 & $1637.1 \pm 16086.2^{F}$ & 32.7 & 1175 & 0.97 & 0.31 & 0.31 & Q \\
\hline & & 3.933 & 2.501 & 0.245 & $13.6 \pm 1.1$ & 32.7 & 1175 & & & & \\
\hline & & 3.933 & 3.676 & 0.014 & $6.7 \pm 0.1$ & 32.7 & 1175 & & & & \\
\hline & & 3.933 & 2.419 & 0.283 & $4.6 \pm 0.1$ & 32.7 & 1175 & & & & \\
\hline \multirow[t]{2}{*}{$2251+158$} & 145 & 2.767 & 1.864 & 0.273 & $11.8 \pm 1.1$ & 25.2 & 885 & & & & \\
\hline & & 2.767 & 2.877 & 0.006 & $6.3 \pm 0.2$ & 25.2 & 885 & & & & \\
\hline $2254+074$ & 048 & 0.129 & 0.138 & 0.273 & $15.0 \pm 5.3^{P}$ & 17.5 & 47 & & & & \\
\hline $2254+074$ & 080 & 0.134 & 0.096 & 1.000 & $15.9 \pm 8.2^{F}$ & 19.6 & 79 & 0.93 & 0.25 & 0.31 & B \\
\hline $2254+074$ & 145 & 0.129 & 0.128 & 0.379 & $16.8 \pm 5.6^{P}$ & 19.3 & 79 & & & & \\
\hline $2335+031$ & 048 & 0.085 & 0.058 & 1.000 & $0.4 \pm 0.0^{F}$ & 18.7 & 48 & & & & \\
\hline $2335+031$ & 080 & 0.118 & 0.068 & 1.000 & $0.1 \pm 0.0^{F}$ & 19.4 & 65 & 0.75 & 0.22 & 0.32 & G \\
\hline $2335+031$ & 145 & 0.041 & 0.026 & 1.000 & $0.1 \pm 0.0^{F}$ & 18.1 & 56 & & & & \\
\hline $2345-167$ & 048 & 0.438 & 0.425 & 0.508 & $61.7 \pm 129.8^{F}$ & 12.4 & 70 & & & & \\
\hline $2345-167$ & 080 & 0.510 & 0.440 & 0.805 & $37.7 \pm 31.6^{F}$ & 20.3 & 92 & 0.96 & 0.21 & 0.24 & Q \\
\hline $2345-167$ & 145 & 0.391 & 0.509 & 0.018 & $1.8 \pm 0.1$ & 9.4 & 32 & & & & \\
\hline $2351+456$ & 048 & 0.154 & 0.165 & 0.083 & $11.8 \pm 1.9$ & 18.9 & 129 & & & & \\
\hline $2351+456$ & 080 & 0.179 & 0.124 & 1.000 & $984.2 \pm 35121.0^{F}$ & 19.7 & 69 & 0.95 & 0.14 & 0.19 & Q \\
\hline $2351+456$ & 145 & 0.190 & 0.150 & 0.821 & $13.5 \pm 3.8^{F}$ & 19.6 & 149 & & & & \\
\hline
\end{tabular}

Table 1. continued.

\begin{tabular}{lrrrrrrrrrrr}
\hline \hline Designation & Freq & $\delta_{N}$ & A & Fap & Tms & ObT & $N$ & VI & NVA & RMSD & ID \\
\hline $2352+495$ & 048 & 0.094 & 0.057 & 1.000 & $0.4 \pm 0.0^{F}$ & 14.5 & 57 & & & & \\
$2352+495$ & 080 & 0.140 & 0.101 & 1.000 & $62.3 \pm 208.8^{F}$ & 13.7 & 58 & 0.85 & 0.11 & 0.19 & Q \\
$2352+495$ & 145 & 0.095 & 0.077 & 0.996 & $714.7 \pm 22042.4^{F}$ & 14.3 & 61 & & & & \\
\hline $2356+196$ & 048 & 0.135 & 0.156 & 0.900 & $0.7 \pm 1.0^{F}$ & 0.7 & 3 & & & & \\
$2356+196$ & 080 & 0.102 & 0.100 & 0.900 & $0.2 \pm 0.0^{F}$ & 16.9 & 26 & 0.86 & 0.13 & 0.27 & $\mathrm{Q}$ \\
$2356+196$ & 145 & 0.045 & 0.039 & 1.000 & $0.1 \pm 0.0^{F}$ & 2.0 & 22 & & & & \\
\hline
\end{tabular}

